\title{
Influence of process parameters for sheet lamination based on laser micro-spot welding of austenitic stainless steel sheets for bone tissue applications
}

\author{
Luis D. Cedeño-Viveros ${ }^{1,2} \cdot$ Elisa Vázquez-Lepe ${ }^{1,2} \cdot$ Ciro A. Rodríguez $^{1,2} \cdot$ Erika García-López $^{1,2}$ (B)
}

Received: 3 December 2020 / Accepted: 15 April 2021 / Published online: 8 May 2021

(C) The Author(s) 2021

\begin{abstract}
The laser micro-spot welding process was studied to implement a sheet lamination process-based methodology for the fabrication of austenitic stainless steel scaffolds. AISI 302 sheets with a thickness of $254 \mu \mathrm{m}$ were laser cut and laser welded. Experimental tests were carried out with different values of average laser power (i.e., 180, 200, and $220 \mathrm{~W}$ ) and different exposure times (25, $50,75,100,125 \mathrm{~ms}$ ). The micro-spot welds were visually inspected according to the ISO 13919-1 Class B requirements. Spot welds were qualitatively characterized, and weld dimensions were measured (i.e., penetration depth, top, middle, and bottom width and the heat-affected zone (HAZ)) to identify the cross-sectional shape. Furthermore, process efficiencies (i.e., coupling, melting, and process) were studied. A seam welding model was adapted to calculate the required exposure time and was used to obtain a micro-spot weld to accomplish the quality requirements of the scaffold. A scaffold prototype was designed and manufactured using the selected parameters by experimental trials and using the mathematical model (i.e., a laser power of $220 \mathrm{~W}$ and an exposure time of $45 \mathrm{~ms}$ ).
\end{abstract}

Keywords Laser micro-spot welding $\cdot$ Stainless steel $\cdot$ Sheet lamination $\cdot$ Metallic scaffolds

\section{Introduction}

Scaffolds for bone tissue engineering have been developed to deal with the increased need of reconstruction procedures in orthopedics due to trauma, tumor, deformity, degeneration, and an aging population [1]. Porous metallic scaffolds for long-term replacement of bone defects provide an interfacial porosity as well as a permanent structural framework. Although there are several biocompatible metallic materials (i.e., stainless steel, magnesium alloys, titanium alloys, $\mathrm{Ni}-\mathrm{Ti}$ alloys, and tantalum) frequently used in the replacement of bone in dental and orthopedic surgery, AISI 316L stainless steel alloy has been employed as a standard surgical material [2]. Additionally, AISI 302 and AISI 304 alloys are commonly used for orthodontic wires due to their high strength,

Erika García-López

garcia.erika@tec.mx

1 Tecnologico de Monterrey, Escuela de Ingeniería y Ciencias, Ave. Eugenio Garza Sada 2501, 64849 Monterrey, N.L., Mexico

2 Laboratorio Nacional de Manufactura Aditiva y Digital (MADiT), 66629 Apodaca, N.L., Mexico elasticity, and formability additional to its low manufacturing cost. Besides, these materials achieve the biocompatibility feature in stomatognathic tissues [3].

Laser-based additive processes present high potential in the fabrication of scaffolds due to its ability to produce complex geometries that mimic the structure and mechanical properties of the human bone despite its high cost of implementation and lack of ability to produce high volumes [4]. For example, Dewidar et al. [5] fabricated austenitic AISI 316L stainless steel scaffolds with a $50 \%$ porosity, an elastic modulus, and a compression strength close to the human's cortical bone through the selective laser sintering (SLS) process. Čapek and Vojtěch [6] explored the mechanical properties (i.e., tensile, compressive, and flexural tests) of austenitic AISI 316L stainless steel to produce highly porous cylindrical scaffolds using selective laser melting (SLM) with mechanical properties close to those of cancellous bone. According to the additive manufacturing terminology standard (ISO/ASTM 52900-15), sheet lamination processes are based on adding layers of sheets which are joined through several manufacturing methods. Xu et al. [7] proposed the microDLOM (double-stage layer object manufacturing) to fabricate stainless steel micro-cavity molds. These molds were produced by laser cutting metallic foils and the resistance slip spot welding 
to join the metallic foils with good surface quality (i.e., $0.07 \mu \mathrm{m}$ of surface roughness) and good accuracy in height direction. Lie et al. [8] fabricated stainless steel micro-electrodes with $\sim 92 \mu \mathrm{m}$ of width using the micro-DLOM and WEDM (wire electrical discharge machining). Hung et al. [9] compared AISI 304L stainless steel parts produced by LFP (laser foil printing) and SLM to analyze the chemical composition and mechanical properties. Their results revealed that the LFP process produces solid parts through laser cutting and laser seam welding with lower oxygen content and higher tensile strength but lower ductility in comparison to the SLM parts. All studies based on sheet lamination process found in the literature were constructed from solid parts and were joined through continuous seam welds. However, to the best of our knowledge, there are no reported articles using spot welding as the joining process. Laser micro-welding is able to join all types of metallic materials and produces joints with high strength, which are consistent with those of the base material [10].

Table 1 presents several studies focused on the laser microwelding of austenitic stainless steels (i.e., AISI 302, AISI 304, and AISI 316). These works analyze the influence of laser welding parameters on weld width and weld penetration depth. Sun et al. [11] studied the influence of different shielding gasses in pore's formation in the laser seam welds of AISI 304 plates with $20 \mathrm{~mm}$ of thickness. The results demonstrated that shielding gas has a great influence in pore formation, and several pores were found in seam welds when $\mathrm{Ar}$ was used, but when $\mathrm{N}_{2}$ or no gas was used, the seam welds presented almost no pores. Kumar et al. [12] performed a comparative study of the laser seam welding of AISI 304 and AISI 316 stainless steel alloys. The results demonstrated that higher linear heat input is required in the AISI 304 alloy compared to the AISI 316 alloy to obtain the maximum ultimate strength of the seam weld. Only two studies have been performed on the laser micro-spot welding of stainless steel alloys [13, 14]. Siva Shanmugam et al. [13] presented a finite element model (FEM) comparing the simulation with experimental trials for the laser micro-spot welding of austenitic AISI 304 stainless steel sheets of $2.5 \mathrm{~mm}$ thickness in bead on plate configuration. Cedeño-Viveros et al. [14] experimentally studied the influence of laser power and focal distances in laser micro-spot welds in austenitic AISI 302 stainless steel sheets of $0.254 \mathrm{~mm}$ of thickness in an overlap joint configuration.

Some mathematical models have been developed to study the influence of process parameters on the process' efficiency and heat disipation. Hipp et al. [15] presented a high-accuracy method for the determination of the coupling and melting efficiency based on measuring the temperature-time curves and laser seam welds conducted in AISI 304 plates of $1 \mathrm{~mm}$. Patschger et al. [16] calculated the process' efficiencies of the laser micro-welding of austenitic AISI 304 stainless steel foils to determine the amount of energy used to melt the material and the amount of energy lost in heat dissipation. Tadamalle et al. [17] studied the welding speed effect in the laser microwelding process through a semi-empirical model which showed high process efficiency at welding speeds of $7 \mathrm{~mm} / \mathrm{s}$ or above. Both models have been focused on determining the process' efficiency of the laser micro-seam welding process using feed rate $(v)$ in the calculations. However, no mathematical model for the laser micro-spot welding (i.e., feed rate equal to zero) melting efficiency calculation was found in literature.

According to Narayan et al. [10], the advantage of using two or more laser-based micro-fabrication processes may play an important role in the future development of the fabrication of biomaterials in different applications (i.e., neural implants, ophthalmic implants, cardiovascular devices, transdermal microneedles). Laser micro-cutting and micro-welding have shown a promising future in the medical industry. For example, laser micro-cutting has demonstrated great potential to fabricate one of the most demanding medical devices,
Table 1 Literature review of the laser micro-welding of austenitic stainless steels

\begin{tabular}{|c|c|c|c|c|c|c|}
\hline Ref. & $\begin{array}{l}\text { Alloy } \\
\text { (thickness) }\end{array}$ & $\begin{array}{l}\text { Welding type } \\
\text { (configuration) }\end{array}$ & $\begin{array}{l}\text { Laser } \\
\text { mode }\end{array}$ & $\begin{array}{l}\text { Laser } \\
\text { power }(\mathrm{W})\end{array}$ & $\begin{array}{l}\text { Weld } \\
\text { width }(\mu \mathrm{m})\end{array}$ & $\begin{array}{l}\text { Weld penetration } \\
\text { depth }(\mu \mathrm{m})\end{array}$ \\
\hline$[13]$ & $\begin{array}{l}\text { AISI } 304 \\
\quad(2.500 \mathrm{~mm})\end{array}$ & $\begin{array}{l}\text { Spot (bead on } \\
\text { plate) }\end{array}$ & $\mathrm{CW}$ & $100-500$ & $827-1696$ & $554-1712$ \\
\hline [14] & $\begin{array}{l}\text { AISI } 302 \\
\quad(0.254 \mathrm{~mm})\end{array}$ & Spot (overlap) & $\mathrm{CW}$ & $100-250$ & $173-3350$ & $108-508$ \\
\hline [24] & $\begin{array}{l}\text { AISI } 304 \\
\quad(0.120 \mathrm{~mm})\end{array}$ & Seam (overlap) & Q-switch & $133-267$ & 300 & 120 \\
\hline [25] & $\begin{array}{l}\text { AISI 316L } \\
\quad(0.200 \mathrm{~mm})\end{array}$ & Seam (overlap) & Pulsed & $250-625$ & $500-700$ & $100-200$ \\
\hline$[16]$ & $\begin{array}{l}\text { AISI } 304 \\
\quad(0.010 \mathrm{~mm})\end{array}$ & Seam (overlap) & $\mathrm{CW}$ & $50-780$ & $22-74$ & $15-50$ \\
\hline$[17]$ & $\begin{array}{l}\text { AISI } 304 \mathrm{~L} \\
\quad(0.500 \mathrm{~mm})\end{array}$ & $\begin{array}{l}\text { Seam (bead on } \\
\text { plate) }\end{array}$ & Pulsed & 1380 & $648-845$ & $100-472$ \\
\hline$[26]$ & $\begin{array}{l}\text { AISI } 316 \\
\quad(0.600 \mathrm{~mm})\end{array}$ & $\begin{array}{l}\text { Seam (bead on } \\
\text { plate) }\end{array}$ & Pulsed & 2000 & $318-737$ & $170-600$ \\
\hline
\end{tabular}


coronary stents, with high accuracy and high-quality surface finish [18]. Additionally, advantages of the laser microwelding process are high precision, due to the small size of the laser spot, non-contact to prevent contamination, and excellent weld quality with low heat input [19]. Although laser micro-cutting and micro-spot welding have not been used for to fabricate 3D metallic scaffolds, Itälä et al. [20] manufactured triangle-shaped titanium scaffolds with standard dimensions (a base of $10 \mathrm{~mm}$, a height of $5 \mathrm{~mm}$, and a thickness of $250 \mu \mathrm{m}$ ) and different pore sizes (i.e., 50, 75, 100, and $125 \mu \mathrm{m}$ ) with a dimensional accuracy of less than $17 \mu \mathrm{m}$ using a laser perforation process. Geng et al. [21] produced pure $\mathrm{Mg}$ scaffolds by laser perforation with round pores of $500 \mu \mathrm{m}$ and with a honeycomb distribution controlling the pore's morphology, size, and the final scaffold porosity. Yu et al. [22] fabricated cylindrical AZ31 magnesium scaffolds with evenly distributed pores with an average $300 \mu \mathrm{m}$ size using laser perforation. The main advantage of the fabrication of metallic scaffolds by the laser perforation method is the simplicity to control the scaffold's structure and the pore's shape, size, and distribution [23].

This work proposed a new related sheet lamination process to produce austenitic stainless steel AISI302 porous scaffolds through a process chain. These 3D structures were fabricated through the laser micro-cutting of thin sheets with miniature patterns stacked in an overlap configuration and joined by laser welding of discrete points. Laser micro-spot welding parameters (i.e., average laser power, exposure time, and beam diameter) were determined based on weld width and penetration depth to produce a class B laser weld based on ISO13919-1 [27] requirements. Welds were studied to analyze the influence of laser welding parameters on the spot weld dimensions, heat-affected zone (HAZ), and the process' efficiency ( $\left.\eta_{\text {pro }}\right)$.

\section{Materials and methods}

\subsection{Material characterization}

The material used was cold rolled and fully hardened AISI 302 austenitic stainless steel sheets (PRECISION BRAND, IL, USA) with a $0.254 \mathrm{~mm}$ thickness. The material selection was based on commercial availability and similar mechanical properties to AISI 316L [5] and cortical bone [28]. The chemical composition of this material is listed in Table 2. This was obtained with atomic absorption spectroscopy method (Laboratorios Fairchild, NL, Mexico) based on ASTM E1024 [29].

\subsection{Stack sample laser experiments}

Based on our previous results, an average laser power $\left(P_{\mathrm{AVG}}\right)$ of $175 \mathrm{~W}$, an exposure time $(t)$ of $250 \mathrm{~ms}$, and a laser
Table 2 Chemical composition of the AISI 302 sheets

\begin{tabular}{llllllll}
\hline $\mathrm{C}$ & $\mathrm{Cr}$ & $\mathrm{Ni}$ & $\mathrm{Mn}$ & $\mathrm{P}$ & $\mathrm{S}$ & $\mathrm{Si}$ & $\mathrm{Mo}$ \\
\hline 0.05 & 17.5 & 8.1 & 0.87 & 0.003 & 0.002 & 0.25 & 0.19 \\
\hline
\end{tabular}

measured spot diameter $\left(d_{\mathrm{f}}\right)$ of $193 \mu \mathrm{m}$ promoted wellformed micro-spot welds and enabled the overlap joint of two AISI 302 sheets of $254 \mu \mathrm{m}$ of thickness [14]. A process parameter validation was performed before proceeding to build a porous scaffold. The aim of the study was to achieve higher penetration depth $(h)$ and to assure the proper joint of the three AISI 302 sheets. The experiments were performed in a MedPro machine (Preco Inc, WI, USA). This machine has an YLR-150/1500-QCW-AC fiber laser source from IPG photonics (IPG photonics, MA, USA) adapted to a fiber core diameter of $50 \mu \mathrm{m}$. The beam was focused using a $60-\mathrm{mm}$ collimating lens, and a 50-mm focal lens, resulting in a theoretical spot size of $42 \mu \mathrm{m}$. For laser cutting experiments, the laser was set in a modulated continuous wave operating mode; for laser welding, a continuous wave mode was used. A graphical view of the laser's micro-spot welding input variables (i.e., average laser power and exposure time) and fixed conditions (i.e., laser spot diameter, shielding gas flux, shielding gas pressure, and assist gas pressure) is shown in Fig. 1. An average laser power $\left(P_{\mathrm{AVG}}\right)$ range of $180-220 \mathrm{~W}$ was selected, the exposure time $(t)$ range was $25-125 \mathrm{~ms}$, and the laser spot diameter $\left(d_{\mathrm{f}}\right)$ was set to $193 \mu \mathrm{m}$. The laser beam spot size was defocused $3 \mathrm{~mm}$ from the focal plane. The shielding argon gas flux $(\mathrm{fx})$ remained constant at $11 \mathrm{~L} / \mathrm{min}$ and the pressure of the shielding gas $\left(P_{\mathrm{SG}}\right)$ and assist gas $\left(P_{\mathrm{G} 1}\right)$ was near to 0 Psi. Figure 2a presents the arrangement of the three sheets stacked in an overlap setting, and welding positions (p1, p2) and geometrical dimensions are presented in Fig. 2b, c, respectively. The input variables of average laser power $\left(P_{\mathrm{AVG}}\right)$ and exposure time $(t)$ with their respective values of total heat input $\left(Q_{\mathrm{tot}}\right)$ and laser spot diameter $\left(d_{\mathrm{f}}\right)$ for experimental tests are listed in Table 3.

\subsection{Stack sample characterization}

Samples were mounted in polyester resin (Poliformas, NL, Mexico) and then were axially cut outside the laser microspot weld using a silicon carbide disk cutter. The sectioned samples were prepared in accordance with the specifications of the ASTM E3-11 [30] standard (Standard Guide for Preparation of Metallographic Specimens). Laser spot welds were polished with an alumina (particle size $\sim 0.5 \mu \mathrm{m}$ ) and chemically etched with Marble's reagent $(50 \mathrm{~mL} \mathrm{HCl}+10 \mathrm{~g}$ $\mathrm{CuSO}_{4}+50 \mathrm{~mL} \mathrm{H}_{2} \mathrm{O}$ ). Measurements of the laser micro-spot welds (i.e., top width $\left(w_{\mathrm{T}}\right)$, middle width $\left(w_{\mathrm{M}}\right)$, bottom width $\left(w_{\mathrm{B}}\right)$, and penetration depth $\left.(h)\right)$ were carried out using an 


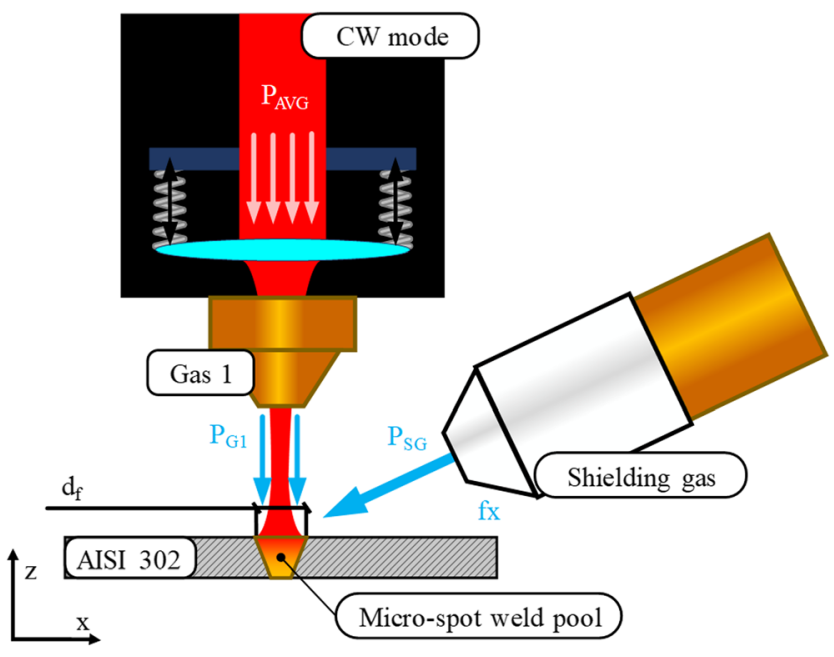

Fig. 1 Laser micro-spot welding process parameters

inverted PMG3 optical microscope (Olympus, Tokyo, Japan). Welding defects, such as pore size, lack of penetration, incompletely filled grooves, root cavity, excessive weld metal, and excessive penetration, were measured using ImageJ software (National Institute of Health, MD, USA).

There is no standard for the evaluation by visual inspection of laser micro-spot welds. However, ISO 13919-1 [27] is the current standard to evaluate the laser seam welds in steel by visual inspection. In our investigation, the total material thickness of the three AISI 302 sheets was $762 \mu \mathrm{m}$, which accomplishes the ISO 13919-1 standard requirement (i.e., a minimum total thickness of $500 \mu \mathrm{m})$. Also, the standard establishes three quality classes for the visual inspection of laser welds (i.e., B, C, and D). Considering that the final application of the laser micro-spot weld is the fabrication of metallic scaffolds for bone implants, Class B was selected as the quality level to accomplish, according to the weld defect and their failure consequences. Additionally, ISO 13919-1 [27] presented the possibility to establish limits for the visual quality evaluation according to calculations referenced by the total thickness of the laser-welded joint. This approach was extrapolated to evaluate the laser micro-spot welds of this investigation.
Table 3 Input variables for the laser micro-spot welding experiments

\begin{tabular}{lll}
\hline $\begin{array}{l}\text { Average laser power, } P_{\text {AVG }} \\
(\mathrm{W})\end{array}$ & $\begin{array}{l}\text { Exposure time, } t \\
(\mathrm{~ms})\end{array}$ & $\begin{array}{l}\text { Heat input, } Q_{\text {in }} \\
(\mathrm{J})\end{array}$ \\
\hline 180 & 25 & 4.5 \\
& 50 & 9.0 \\
& 75 & 13.5 \\
& 100 & 18.0 \\
& 125 & 22.5 \\
200 & 25 & 5.0 \\
& 50 & 10.0 \\
& 75 & 15.0 \\
& 100 & 20.0 \\
220 & 125 & 25.0 \\
& 25 & 5.5 \\
& 50 & 11.0 \\
& 75 & 16.5 \\
& 100 & 22.0 \\
& 125 & 27.5 \\
\hline
\end{tabular}

For the detection of incomplete filled groove, the limit was calculated and set to $38 \mu \mathrm{m}$ (i.e., $5 \%$ of the total material thickness). For the detection of root cavity, the limit was calculated and set to $76 \mu \mathrm{m}$ (i.e., $10 \%$ of the total material thickness) (see Fig. 3a). The limit for the maximum pore size was calculated and set to $22 \mu \mathrm{m}$ (i.e., $3 \%$ of the total material thickness). Lack of penetration should be less than $15 \%$ of the total penetration depth $(h)$ of the micro-spot weld (Fig. $3 \mathrm{~b})$. For the detection of excessive penetration defect, the limit was set to $114 \mu \mathrm{m}$ (15\% of the total material thickness) (Fig. $3 c)$. Using the limits established for the lack of penetration and excessive penetration, two specification limits were established for the penetration depth $(h)$ of the laser microspot welds. The central specification limit (CSL) is the total thickness of the three stacked sheets (i.e., $762 \mu \mathrm{m}$ ). The lower specification limit (LSL) was established adding the lack of penetration limit $(0.15 \mathrm{~h})$ to the penetration depth $(h)$. This is equal to the thickness of three stacked sheets. LSL resulted in (a)

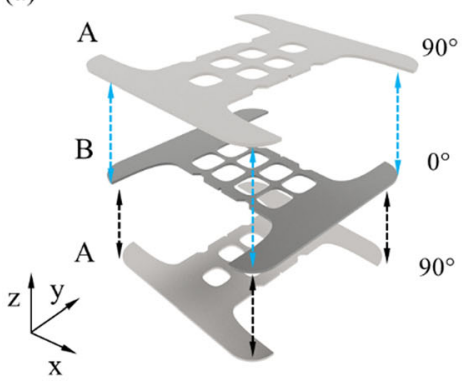

(b) $\circ \mathrm{p} 1-\mathrm{p} 2$

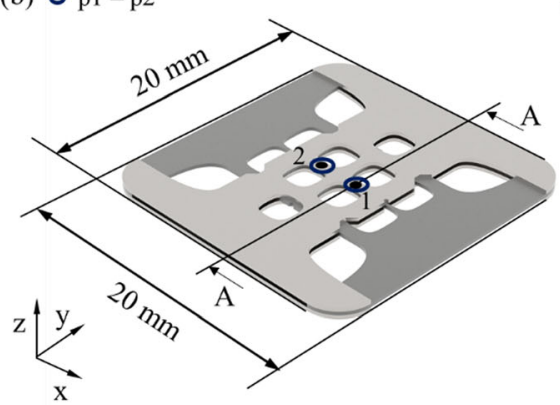

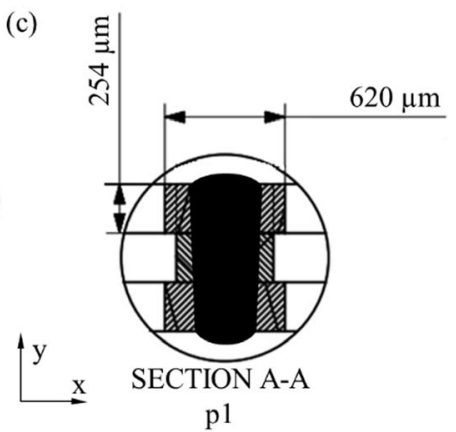

(c) p1

Fig. 2 a Sample arrangement, b sample assembly and spot positions, and $\mathbf{c}$ sectional view for the laser micro-spot welding of AISI 302 sheets 
$663 \mu \mathrm{m}$ and represented the minimum depth penetration required to avoid lack of penetration. The upper specification limit (USL) was set to $876 \mu \mathrm{m}(\mathrm{CSL}+114 \mu \mathrm{m}$ of excessive penetration) and it represented the maximum permitted penetration depth (Fig. 3d). Based on these specification limits, all the laser spot weld defects were visually inspected and evaluated to assure the manufacture Class B laser micro-spot welds.

\subsection{Porous scaffold fabrication}

The fixture designed for stacked experiments was modified. The top clamp consisted of a plate with holes of $3 \mathrm{~mm}$ in diameter. This configuration allowed the laser beam to pass through holes and perform the micro-spot welds without air gap defects. The proposed methodology was created to generate a porous structure manufactured by a new related sheet lamination process. The porous metallic scaffold was designed using NX 10 software (Siemens, USA) resulting in a theoretically calculated porosity of $47 \%$. It was corroborated by measuring the relative density using Archimedes' principle, which resulted in an experimental porosity of around $46 \%$. The base dimension of the designed scaffold was $10.3 \mathrm{~mm} \times 10.3 \mathrm{~mm}$ with a height of $5.3 \mathrm{~mm}$. It was composed of circular pores with a $2.54 \mathrm{-mm}$ diameter and $1 \mathrm{~mm} \times 0.254 \mathrm{~mm}$ rectangular struts. According to the strut size, three metallic sheets of $254 \mu \mathrm{m}$ of thickness were joined in an overlap joint configuration. A shape factor was defined as the penetration depth $(h)$ divided by the spot width $(w)$ to accomplish the spot weld dimension in the designed struts
[31]. According to the scaffold design, the shape factor of the micro-spot weld must be between 1.0 (i.e., $h \geq 663 \mu \mathrm{m}$ and $w_{\mathrm{T}} \geq 620 \mu \mathrm{m}$, see Fig. $4 \mathrm{c}$ ) and 1.4 to assure that the spot weld achieves full penetration based on the ISO 13919-1 [27]. An overview of the sheet lamination methodology used for the scaffold's construction is illustrated in Fig. 4. Twenty-one square AISI 302 sheets $(20 \times 20 \mathrm{~mm})$ with a $254 \mu \mathrm{m}$ thickness were laser cut from an AISI 302 shims (Fig. 4a). A hole was pre-drilled at each cutting operation to enable a faster geometry detachment. Table 4 lists the process parameters of the laser micro-cutting and laser drilling operations. According to García-López et al. [32], these process parameters assure a pulse overlapping of over $50 \%$ which reduces considerably the surface roughness on the edge of the strut. All sheets were cleaned in an ultrasonic bath with isopropanol alcohol before the pieces were welded. Figure $4 \mathrm{~b}$ illustrates the geometry shape and the internal patterns of the scaffold design. Three metallic sheets were stacked and aligned in a laid down orientation at $90^{\circ}, 0^{\circ}$, and $90^{\circ}$, respectively (Fig. 4c). These sheets were joined with four laser spot welds. Figure $4 d$ illustrates the position of these four laser micro-spot welds $(\mathrm{p} 1-\mathrm{p} 4)$. The spot weld positions of the laser are alternated with the positions of the micro-spot welds (p5-p8) to avoid mechanical deformation in the sheets due to heat concentration (see Fig. 4e). After the laser micro-spot welding operations, a metallic preform was obtained. The frame was cut away using wire electrical discharge machining (WEDM). Figure 4 f illustrates the porous metallic scaffold prototype manufactured.
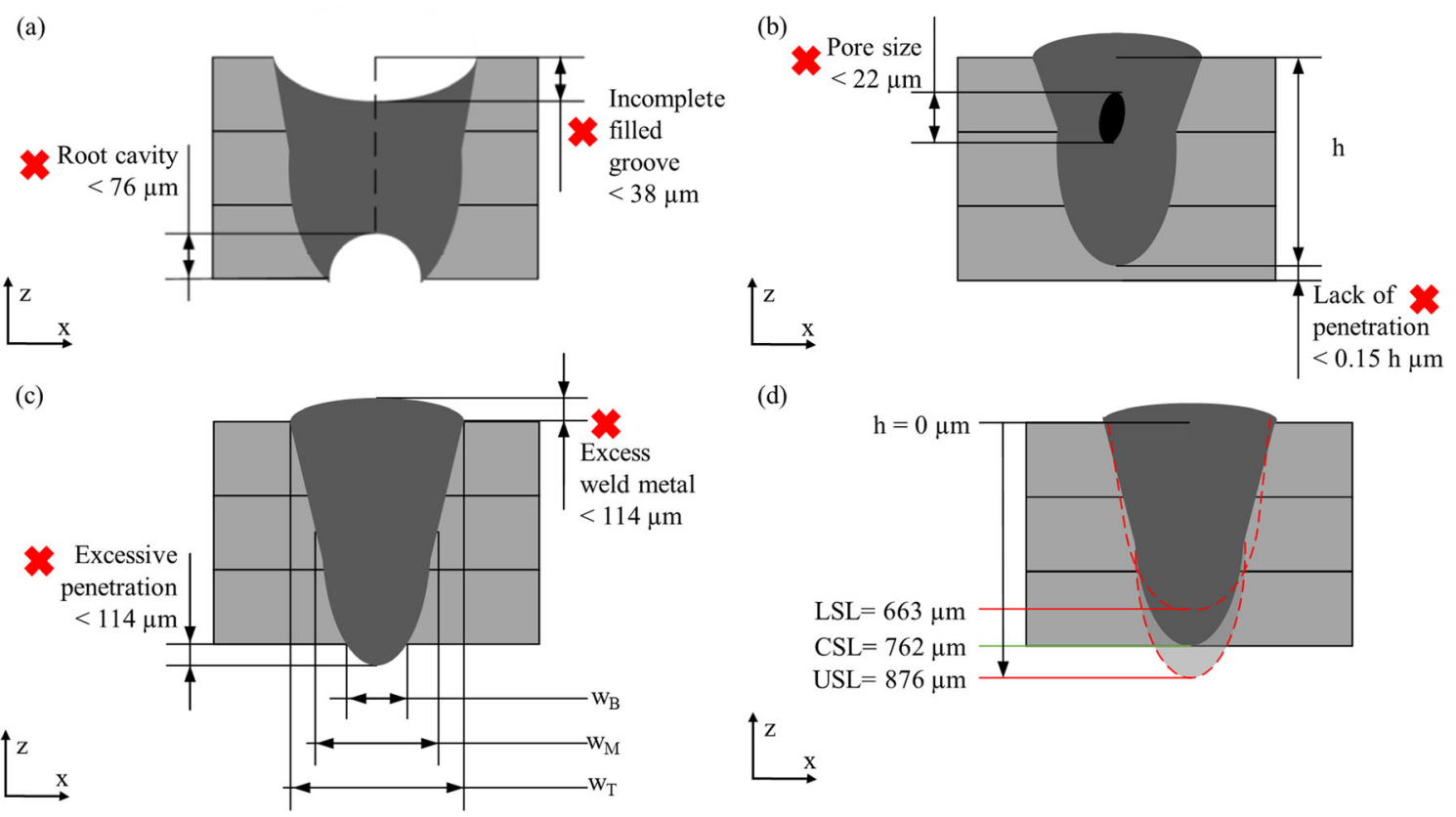

(d)

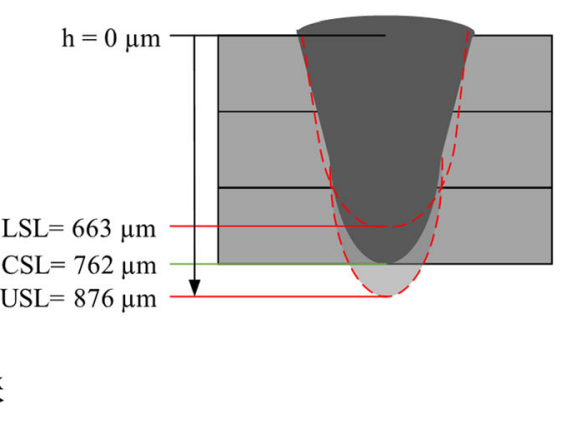

Fig. 3 Specification limits for a incomplete filled grooves and root cavities; $\mathbf{b}$ pore size and lack of penetration; $\mathbf{c}$ excessive weld metal and excessive penetration welding defects according to the ISO 13919-1; and d upper, central, and lower specification limits for spot weld profile 
Table 4 Parameters used for laser drilling and laser micro-cutting operations

\begin{tabular}{llll}
\hline Process parameters & & Laser drilling & Laser micro-cutting \\
\hline Average laser power & $P_{\mathrm{AVG}}(\mathrm{W})$ & 180 & 170 \\
Pulse frequency & $f(\mathrm{~Hz})$ & 1500 & 1100 \\
Dwelling time & $t_{\mathrm{D}}(\mathrm{ms})$ & 400 & - \\
Pulse width & $t_{\mathrm{W}}(\mu \mathrm{s})$ & 160 & 218 \\
Feed rate & $v(\mathrm{~mm} / \mathrm{min})$ & - & 200 \\
Assist gas pressure $\left(\mathrm{N}_{2}\right)$ & $P_{\mathrm{G} 1}(\mathrm{Psi})$ & 150 & 150 \\
\hline
\end{tabular}

\section{Mathematical model}

\subsection{Material's properties}

With rising temperature, density $(\rho)$ is substantially constant, but electrical resistivity $(R(T))$, specific heat $(\mathrm{Cp}(T))$, and thermal diffusivity $(\kappa(T))$ presented considerable variations over the temperature interval between ambient temperature $\left(T_{0}\right)$ of $300 \mathrm{~K}$ and melting temperature $\left(T_{\mathrm{m}}\right)$ of $1693 \mathrm{~K}$ [33]. To deal with the temperature-dependent variations, average values for the thermal properties (i.e., electrical resistivity, thermal conductivity, and specific heat) were calculated [34]. Data regarding AISI 302 thermal properties (i.e., electrical resistivity, thermal conductivity, and specific heat) were collected from the Handbook of Stainless Steels [33]. Regression models were fitted to the data of the AISI 302 alloy and average values for each material property were estimated in the temperature interval from the ambient temperature $\left(T_{0}\right)$ to the melting

temperature $\left(T_{\mathrm{m}}\right)$ using Eqs. (1-3) [35]. The absorptance $(A)$ of the materials was calculated using Eq. (4) proposed by $\mathrm{He}$ et al. [36] where $\lambda$ is the laser beam's wavelength (i.e., $1074 \mathrm{~nm}$ for fiber laser) and $R_{\mathrm{AVG}}$ is the average electrical resistivity aforementioned. Table 5 presents the calculated values of the average electrical resistivity $\left(R_{\mathrm{AVG}}\right)$, the average specific heat $\left(\mathrm{Cp}_{\mathrm{AVG}}\right)$, the average thermal diffusivity $\left(\kappa_{\mathrm{AVG}}\right)$, and the absorptance $(A)$ for AISI 302 alloy. A density $(\rho)$ of $8000 \mathrm{~kg} / \mathrm{m}^{3}$ and the latent heat of fusion $\left(h_{\mathrm{f}}\right)$ of $2.6 \times 105 \mathrm{~J} / \mathrm{kg}$ were used for the calculations [33, 37].

$$
\begin{aligned}
R_{\mathrm{AVG}} & =\int_{T_{0}}^{T_{\mathrm{m}}} \frac{R(T)}{T_{\mathrm{m}}-T_{0}} d T \\
\mathrm{Cp}_{\mathrm{AVG}} & =\int_{T_{0}}^{T_{\mathrm{m}}} \frac{\mathrm{Cp}(T)}{T_{\mathrm{m}}-T_{0}} d T \\
\kappa_{\mathrm{AVG}} & =\int_{T_{0}}^{T_{\mathrm{m}}} \frac{\kappa(T)}{T_{\mathrm{m}}-T_{0}} d T
\end{aligned}
$$

(a)

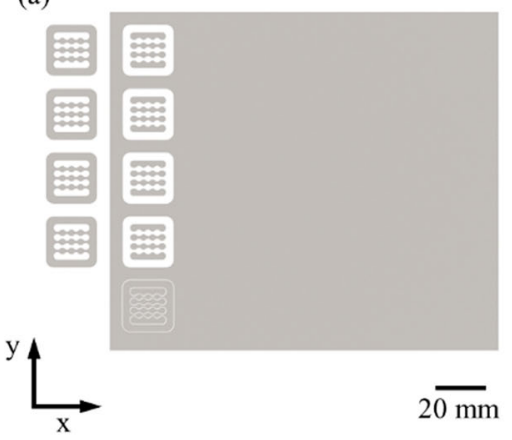

(d)

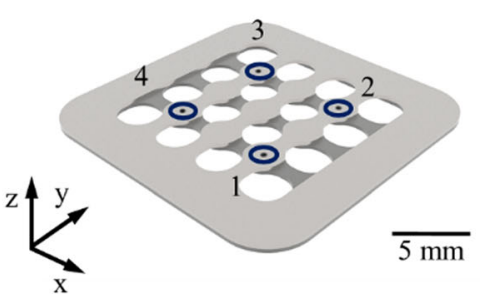

(b)

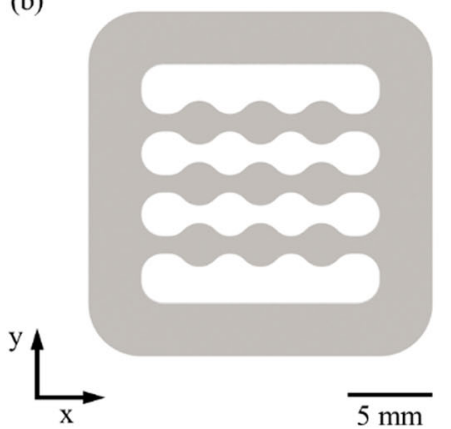

(e) $\circ \mathrm{p} 5-\mathrm{p} 8$

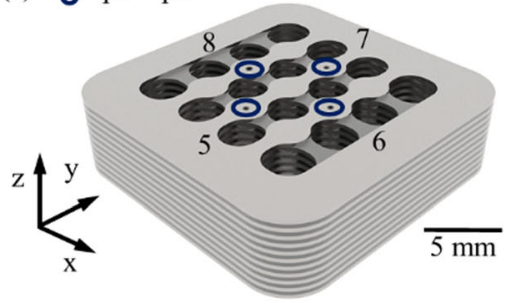

(c)

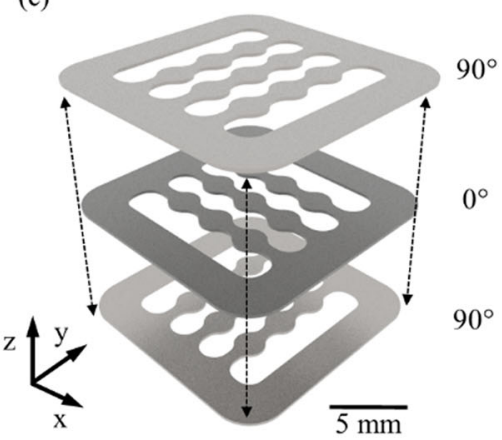

(f)

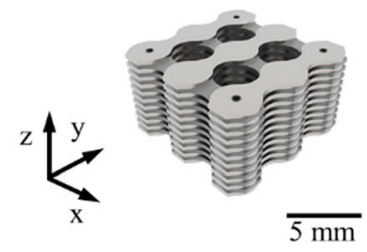

Fig. 4 Graphical view of the proposed methodology for the manufacturing of metallic scaffolds: a laser micro-cutting of sheets, $\mathbf{b}$ internal geometry of AISI 302 sheets, $\mathbf{c}$ laid down pattern of three sheets, d intercalated positions for the laser micro-spot welds p1-p4, e alternated position for the laser micro-spot welds $\mathrm{p} 5-\mathrm{p} 8$, and $\mathbf{f}$ AISI 302 metallic scaffold 


$$
\begin{aligned}
A= & 0.365\left(\frac{R_{\mathrm{AVG}}}{\lambda}\right)^{1 / 2}-0.0667\left(\frac{R_{\mathrm{AVG}}}{\lambda}\right) \\
& +0.006\left(\frac{R_{\mathrm{AVG}}}{\lambda}\right)^{3 / 2}
\end{aligned}
$$

\subsection{Process efficiency modeling}

For laser micro-seam welding, the laser beam moves at a constant speed, while in the laser micro-spot welding process, the laser beam remains static which indicates a feed rate $(v)$ equal to $0 \mathrm{~mm} / \mathrm{s}$. This model uses the final weld dimensions (i.e., penetration depth $(h)$, top width $\left(w_{\mathrm{T}}\right)$, and bottom width $\left.\left(w_{\mathrm{B}}\right)\right)$, the welding parameters (average laser power $\left(P_{\mathrm{AVG}}\right)$ and the exposure time $(t)$ ), and the thermophysical properties of the material (i.e., absorptance, average specific heat, latent fusion heat, and density) to estimate the process' efficiency $\left(\eta_{\text {pro }}\right)$. The process' efficiency ( $\left.\eta_{\text {pro }}\right)$ of the laser welding processes $[15,35]$ is commonly split into two separate terms (Eq. (5)). To minimize the heat dissipation loss during the laser micro-spot welding process, the process' efficiency $\left(\eta_{\text {pro }}\right)$ should be maximized, which is of considerable interest in the fabrication of scaffolds.

$\eta_{\text {pro }}=\eta_{\mathrm{C}} \eta_{\mathrm{M}}$

where $\eta_{\mathrm{C}}$ is the coupling efficiency and $\eta_{\mathrm{M}}$ the melting efficiency.

\subsubsection{The coupling efficiency}

The coupling efficiency $\left(\eta_{\mathrm{C}}\right)$ is defined in terms of energy as the ratio between the heat input transferred $\left(Q_{\text {trans }}\right)$ to the material and the total heat input $\left(Q_{\text {tot }}\right)$ (see Eq. (6)) $[15,35]$. The total heat input $\left(Q_{\mathrm{tot}}\right)$ is calculated with Eq. (7) where $P_{\mathrm{AVG}}$ is the average laser power in $\mathrm{W}$ and $t$ is the exposure time in $\mathrm{s}$. Additionally, the Gouffe-Dausinger model establishes a relationship between the coupling efficiency $\left(\eta_{\mathrm{C}}\right)$ and welding conditions using Eq. (8), where $d_{\mathrm{f}}$ is the laser spot diameter, $h$ is the penetration depth, and $A$ is the absorptance of the material previously calculated [38].

Table 5 Results of calculations of the AISI 302 material's properties

\begin{tabular}{ll}
\hline Electrical resistivity, $R_{\mathrm{AVG}}(\mu \Omega \mathrm{cm})$ & 9.98 \\
Average specific heat, $\mathrm{Cp}_{\mathrm{AVG}}(\mathrm{J} / \mathrm{kg} \mathrm{K})$ & 544 \\
Average thermal diffusivity, $\kappa_{\mathrm{AVG}}\left(\mathrm{mm}^{2} / \mathrm{s}\right)$ & 4.35 \\
Absorptance, $A$ & 0.32
\end{tabular}

$$
\begin{aligned}
& \eta_{\mathrm{C}}=\frac{Q_{\text {trans }}}{Q_{\mathrm{tot}}} \\
& Q_{\mathrm{tot}}=P_{\mathrm{AVG}} t \\
& \eta_{\mathrm{C}}=A \frac{1+(1-A)\left[\frac{h}{2 d_{\mathrm{f}}}-\left(\frac{h}{2 d_{\mathrm{f}}}\right)^{2}\right]}{A\left(1+\frac{h}{2 d_{\mathrm{f}}}\right)+\frac{h}{2 d_{\mathrm{f}}}}
\end{aligned}
$$

\subsubsection{The melting efficiency}

The melting efficiency $\left(\eta_{\mathrm{M}}\right)$ is defined by the ratio of the melting heat input $\left(Q_{\text {melt }}\right)$ over the transferred heat input $\left(Q_{\text {trans }}\right)$ (Eq. (9)). The melting heat input $\left(Q_{\text {melt }}\right)$ (Eq. (10)) represents the amount of energy needed to heat up the material to its melting point and achieve the phase change [39]. Where $V$ is the melted pool volume in $\mathrm{m}^{3}, \rho$ is the density in $\mathrm{kg} / \mathrm{m}^{3}$, $\mathrm{Cp}_{\mathrm{AVG}}$ is the average specific heat in $\mathrm{J} / \mathrm{kg} \mathrm{K}, T_{\mathrm{m}}$ is the melting temperature $\mathrm{K}, T_{0}$ is the ambient temperature in $\mathrm{K}$, and $h_{\mathrm{f}}$ is the latent heat of fusion in $\mathrm{J} / \mathrm{kg}$. Melting efficiency $\left(\eta_{\mathrm{M}}\right)$ was calculated using Eq. (11) derived from the substitution of Eqs. (6), (7), and (10) in Eq. (9).

$\eta_{\mathrm{M}}=\frac{Q_{\mathrm{melt}}}{Q_{\mathrm{trans}}}$

$Q_{\text {melt }}=V \rho\left[\operatorname{Cp}_{\mathrm{AVG}}\left(T_{\mathrm{m}}-T_{0}\right)+h_{\mathrm{f}}\right]$

$\eta_{\mathrm{M}}=\frac{V \rho\left[\mathrm{Cp}_{\mathrm{AVG}}\left(T_{\mathrm{m}}-T_{0}\right)+h_{\mathrm{f}}\right]}{\eta_{\mathrm{C}} P_{\mathrm{AVG}} t}$

The micro-spot welds obtained in this study presented parabolic, rectangular, and trapezoidal cross-sectional shapes and from a top view, all the spots presented a circular crosssectional shape. Considering these cross-sectional shapes, it was assumed that the spot welds presented revolution geometries (i.e., paraboloid, cylinder, and truncated cone). These revolution geometries are shown in Fig. 5. Therefore, the melted pool volume $(V)$ was estimated with Eqs. (12-14), where the height of all shapes is equal to the penetration depth (h) and the top radius of the paraboloid, cylinder, and truncated cone is equal to half of the spot weld's top width $\left(w_{\mathrm{T}}\right)$. The bottom radius of the truncated cone is equal to half of the spot weld's bottom width $\left(w_{\mathrm{B}}\right)$. Equations (12-14) neglect the amount of material that is partially evaporated from the weld pool during the welding process [37].

$$
\begin{aligned}
& V=\frac{1}{2} \pi\left(\frac{w_{\mathrm{T}}}{2}\right)^{2} h \\
& V=\pi\left(\frac{w_{\mathrm{T}}}{2}\right)^{2} h
\end{aligned}
$$


$V=\frac{1}{3} \pi\left[\left(\frac{w_{\mathrm{T}}}{2}\right)^{2}+\left(\frac{w_{\mathrm{B}}}{2}\right)^{2}+\left(\frac{w_{\mathrm{T}}}{2}\right)\left(\frac{w_{\mathrm{B}}}{2}\right)\right] h$

\subsection{Laser micro-spot welding modelling}

For laser micro-seam welding, Dausinger et al. [40] proposed a model to estimate the required feed rate $(v)$ to achieve a certain penetration depth $(h)$ when the average laser power $\left(P_{\mathrm{AVG}}\right)$ and the laser spot diameter $\left(d_{\mathrm{f}}\right)$ are previously established. This model is based on Eq. (15), where factors $\alpha_{1}$ and $\alpha_{2}$ are process-dependent parameters, $\kappa_{\mathrm{AVG}}$ is the material's thermal diffusivity in $\mathrm{mm}^{2} / \mathrm{s}, \eta_{\mathrm{C}}$ is the coupling efficiency, and $\mathrm{Hp}$ is the material's specific required melting heat in $\mathrm{J} / \mathrm{mm}^{3}[16,40]$. The linear relationship presented in Eq. (15) had been used by Patschger et al. [37] to find the feed rate required for different materials (i.e., steel, nickel, aluminum, and titanium) for full penetration laser micro-seam welding. The specific required heat $(\mathrm{Hp})$ can be calculated using Eq. (16), which is based on the material's density $(\rho)$, average specific heat $\left(\mathrm{Cp}_{\mathrm{AVG}}\right)$, latent heat of fusion $\left(h_{\mathrm{f}}\right)$, and melting temperature $\left(T_{\mathrm{m}}\right)$. A limitation of our study is the missed consideration of the temperature rise produced in the weld pool formation in Eqs. (10) and (16). Further research can be performed to include this term in our model using experimental method or numerical simulation. Experimental test to include this term is measuring the maximum temperature in the weld pool using thermocouples [41] or a thermographic camera [31]. Other methods implicate analytically calculating the temperature distribution on weld pool through numerical models and experimental validation [42, 43].

$\nu \approx \alpha_{1} \frac{\kappa_{\mathrm{AVG}}}{d_{\mathrm{f}}}+\alpha_{2} \frac{\eta_{\mathrm{C}}}{\mathrm{Hp}}\left(\frac{P_{\mathrm{AVG}}}{h\left(d_{\mathrm{f}}\right)}\right)$

$\mathrm{Hp}=\rho\left[\mathrm{Cp}_{\mathrm{AVG}}\left(T_{\mathrm{m}}\right)+h_{\mathrm{f}}\right]$

The difference between the laser micro-seam and microspot welding affects mainly the way to calculate the pool volume melting rate $(\Delta V / \Delta t)$, which estimates the amount of volume that is melted per unit of time. In the laser microseam welding case, the pool volume melting rate $\left(\Delta V / \Delta t_{\text {seam }}\right.$ ${ }_{-\mathrm{w}}$ ) is calculated using Eq. (17) [39], where $A$ is the crosssectional area of the micro-seam weld in $\mathrm{mm}^{2}$ and $v$ is the feed rate in $\mathrm{mm} / \mathrm{s}$. For the laser micro-spot welding, the pool volume melting rate $\left(\Delta V / \Delta t_{\text {spot }-\mathrm{w}}\right)$ can be calculated using Eq. (18), where $V$ is the melted pool volume in $\mathrm{mm}^{3}$ (i.e., it is estimated with Eqs. (12-14) according to the spot weld shape) and $t$ is the exposure time in $\mathrm{s}$.

$$
\begin{aligned}
& \frac{\Delta V}{\Delta t}_{\text {seam-w }}=v a \\
& \frac{\Delta V}{\Delta t}_{\text {spot-w }}=\frac{V}{t}
\end{aligned}
$$

Equation (17) is solved for the feed rate (v) and substituted in Eq. (15) to obtain Eq. (19) that can be used in both laser micro-welding processes. The pool volume melting rate $(\Delta V /$ $\Delta t_{\text {spot-w }}$ ) of Eq. (18) is substituted in Eq. (19) to obtain Eq. (20), which can be used in the laser micro-spot welding to calculate the required exposure time $(t)$ to achieve the defined penetration depth $(h)$, when the average laser power $\left(P_{\mathrm{AVG}}\right)$ and the laser spot diameter $\left(d_{\mathrm{f}}\right)$ have been previously determined.

$$
\begin{aligned}
& \frac{1}{a}\left({\frac{\Delta V}{\Delta t}{ }_{\text {spot- }}}\right) \approx \alpha_{1} \frac{\kappa_{\mathrm{AVG}}}{\Phi_{\mathrm{f}}}+\alpha_{2} \frac{\eta_{\mathrm{C}}}{\mathrm{Hp}}\left(\frac{P_{\mathrm{AVG}}}{h\left(d_{\mathrm{f}}\right)}\right) \\
& \frac{d_{\mathrm{f}}}{a}\left(\frac{V}{t}\right) \approx \alpha_{1} \kappa_{\mathrm{AVG}}+\alpha_{2} \frac{\eta_{\mathrm{C}}}{\mathrm{Hp}}\left(\frac{P_{\mathrm{AVG}}}{h}\right)
\end{aligned}
$$

\section{Results and discussion}

\subsection{Process parameter validation with stacks}

Figure 6 illustrates a graphical representation of heat energy dissipation of the different regimes of the laser micro-welding process. According to Simonds et al. [41], shallow and broad
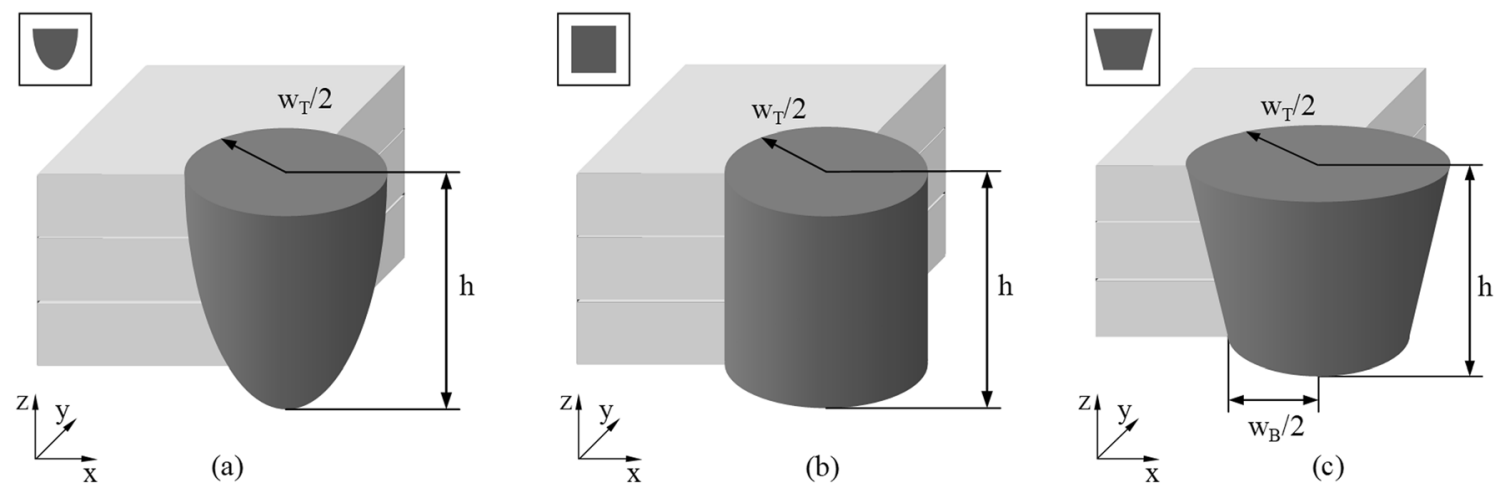

Fig. 5 Welded material volume shape for the laser micro-spot welds with: a parabolic shape, $\mathbf{b}$ cylindrical shape, and $\mathbf{c}$ trapezoidal cross-sectional shape 
cross-sections (Fig. 6a) occurred in a conduction regime. Intermediate cross-sectional shapes that share features of conduction and keyhole are classified as a transition regime (Fig. 6b). Also, Simonds observed that fluted cross-sections (Fig. 6c) are derived from a closed keyhole weld regime. Additionally, Krasnosperov et al. [45] explained that the larger rectangular cross-section (Fig. 6c) resulted from a closed keyhole weld pool while the trapezoidal cross-section arose from an open keyhole regimen (see Fig. 6d).

Figure 7 shows the laser micro-spot welds obtained with the experimental parameters mentioned in Table 3. At the top left corner of each metallography is the geometrical shape of the cross-section of the weld. The vertical axis displays the average laser power $\left(P_{\mathrm{AVG}}\right)$ and the horizontal axis presents the exposure time $(t)$ used for the fabrication of the micro-spot weld. Micro-spot welds fabricated with $220 \mathrm{~W}$ of average laser power $\left(P_{\mathrm{AVG}}\right)$ presented two shape transitions. A crosssection shape transition occurred from 50 to $75 \mathrm{~ms}$ (Fig. 7(b, c)) where the weld shape changed from a rectangle to a trapezoid. Besides, a second cross-section shape transition was observed from 100 to $125 \mathrm{~ms}$ (Fig. 7(d, e)) where the trapezoid shape was inverted. When an average laser power of $200 \mathrm{~W}$ and exposure times $(t)$ of $25 \mathrm{~ms}$ and $50 \mathrm{~ms}$ are used, the micro-spot welds showed rectangular cross-sections (Fig. 7(f, g)), while micro-spot welds with $75 \mathrm{~ms}, 100 \mathrm{~ms}$, and $125 \mathrm{~ms}$ showed a trapezoidal shape (Fig. 7(i, j)). Laser micro-spot welds produced with $180 \mathrm{~W}$ of average laser power $\left(P_{\mathrm{AVG}}\right)$ presented a shape change from semi-circular crosssection at $25 \mathrm{~ms}$ (Fig. 7(k)) to a parabolic cross-section in 50, 75, 100, and $125 \mathrm{~ms}$ (Fig. 7(1-o)).

Only samples performed with $180 \mathrm{~W}$ and $25 \mathrm{~ms}$ (Fig. 7(k)) were identified as conduction regime with a semi-circular cross-section. Additionally, we observed that samples fabricated with heat input of $18 \mathrm{~J}, 22.5 \mathrm{~J}$ (Fig. 7(n, o)), $10 \mathrm{~J}$ (Fig. 7(g)), and $11 \mathrm{~J}$ (Fig. 7(b)) presented a closed keyhole with rectangular and parabolic cross-sectional shapes. Additionally, samples with open keyhole were identified in Fig. $7(\mathrm{c}-\mathrm{e}, \mathrm{h}-\mathrm{j})$, which have a trapezoidal cross-section. In micro-seam welding with bead on plate configuration, the laser beam energy is not uniformly transferred along the $z$ direction and more energy is dissipated in the bottom region of the weld pool, which resulted in a trapezoidal cross-section causing a keyhole regimen [44].

Cedeño-Viveros et al. [14] presented micro-spot welds with semi-circular and parabolic cross-sectional shapes using a calculated intensity $(I)$ between 1.8 and $2.0 \mathrm{~kW} / \mathrm{mm}^{2}$. In our study, the calculated intensity $(I)$ was between 6.2 and 7.5 $\mathrm{kW} / \mathrm{mm}^{2}$, which caused semi-circular, parabolic, cylindrical, and trapezoidal cross-sectional welds. According to Ventrella et al. [25], air gaps in laser welding in overlap configuration act as barrier for heat transfer causing most of the laser beam heat input $\left(Q_{\text {in }}\right)$ to be consumed on the side exposed to the laser beam. In our experiments, we observed air gaps $(\sim 24-34$ $\mu \mathrm{m})$ located between the second and third sheets (Fig. 7(a, g, $\mathrm{h}, \mathrm{k}, \mathrm{m}, \mathrm{n})$ ). We attribute these defects to our fixture design; therefore, a new experimental setup was implemented to avoid air gaps in scaffold design.

Weld defects are showed with a red " $x$ " at the bottom of each metallography in Fig. 7 and the respective nomenclature of the welding defects can be found in Fig. 3a-c. There were no cracks in any of the micro-spot weld samples. This indicates that no hot cracking effects due to stress generation were presented during the heat cycles (i.e., fusion and solidification) [45] and the AISI 302 sheets were properly clamped among sheets.

None of the laser micro-spot welds presented excessive penetration, melt down material, nor excess of weld metal defects. However, almost $50 \%$ of the samples showed a pore in the center of the fusion zone with an average size of $200 \pm$ $11 \mu \mathrm{m}$ (see Fig. 7(b-e, h-j, n)). The central pore defect was observed mainly in samples with rectangular and trapezoidal cross-sections, which indicated the tendency of pore formation in the keyhole welding. According to Sun et al. [11], pores are formed in laser seam welds due to an unstable keyhole formation. Krasnosperov et al. [44] indicated that the closed keyhole weld pool stability range is limited and the keyhole transition from closed to open causes changes in the flow of the weld pool. Furthermore, incompletely filled grooves and root cavity defects were found in samples with trapezoidal cross-sections (Fig. 7(c-e, i, j)). A spattering effect was produced in the center of the fusion zone (Fig. 7(b-e, hj)), which led to high contractions at the top and bottom of the (a)

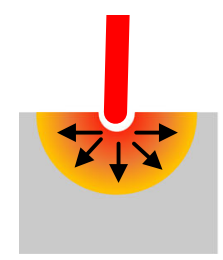

Conduction regime (b)

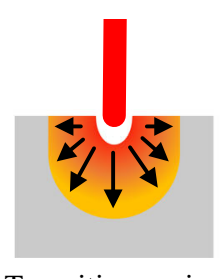

Transition regime (c)

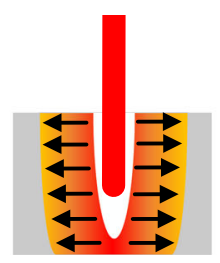

Closed keyhole pool regime Open keyhole pool regime (d)

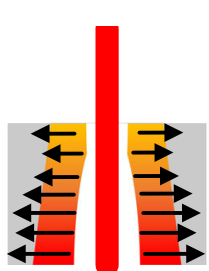

Laser beam

Weld pool

Base material

Fig. 6 Schematic diagram of the heat energy dissipation of the $\mathbf{a}$ conduction, $\mathbf{b}$ transition, $\mathbf{c}$ open, and $\mathbf{d}$ closed keyhole welding regime 
Fig. 7 (a-o) Visual inspection of defects and shape geometries of the laser micro-spot welds obtained for the stack experimental work in AISI 302 stainless steel sheets

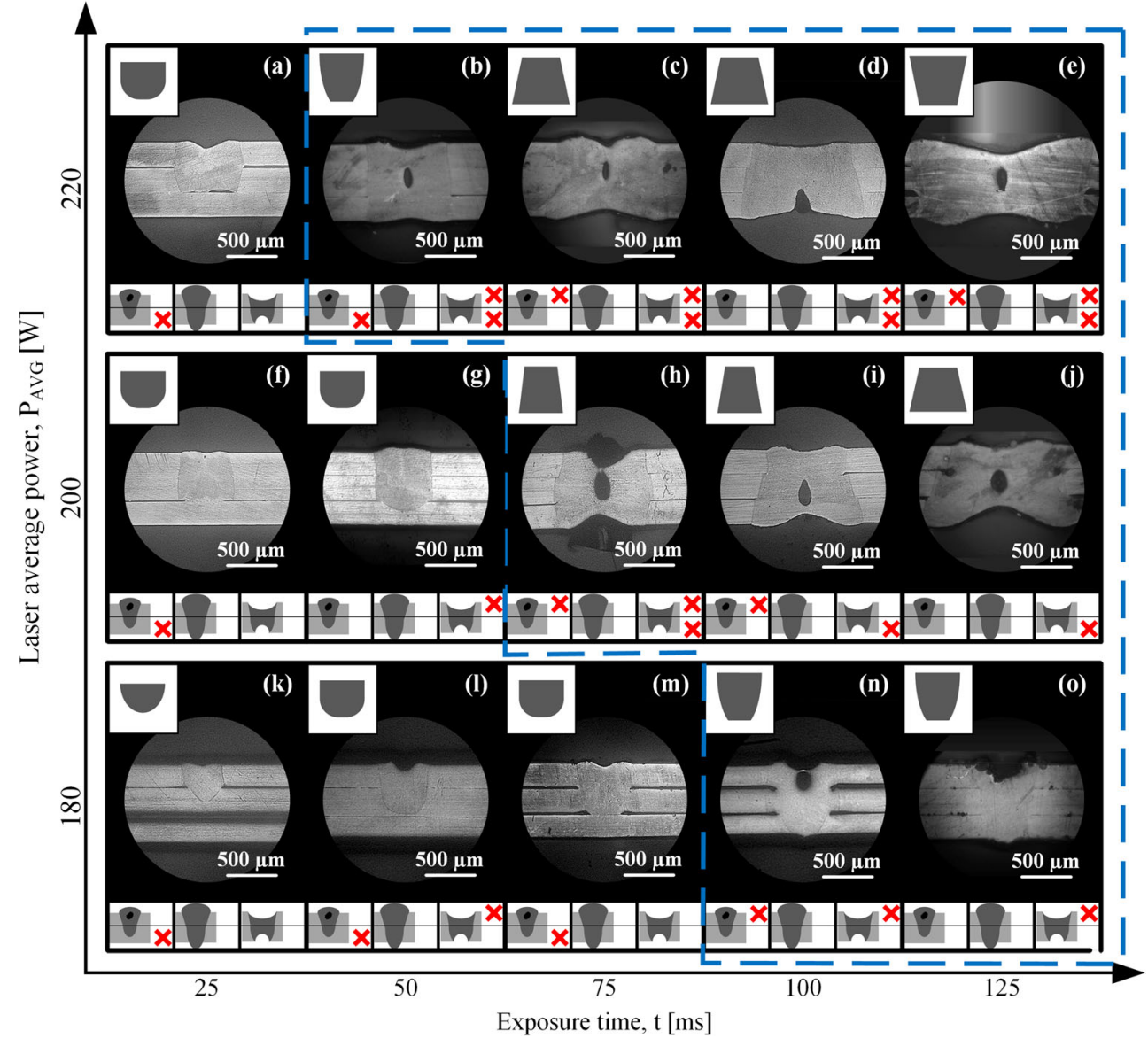

weld pool [46]. Based on our experimental results, it is recommended to remain in the conduction regime or a closed keyhole weld pool to assure weld quality of the final microspot weld and to avoid the formation of pores, incompletely filled grooves, and root cavity defects which may compromise the mechanical strength and integrity of the micro-spot welds. According to the geometrical limits established in Fig. 3d, a range of samples with full penetration are highlighted in Fig. 7(b-e, $\mathrm{h}-\mathrm{j}, \mathrm{n}, \mathrm{o})$. These samples correspond to heat inputs $\left(Q_{\text {in }}\right)$ between 11 and $27.5 \mathrm{~J}$. According to Khan et al., higher values of heat input increase the surface energy density $\left(E_{\mathrm{D}}\right)$ irradiated on the material, which enhanced the transfer of energy in the $z$-direction [47].

Figure 8 illustrates the results for the measured penetration depth $(h)$ against the exposure time $(t)$. Power models were fit and coefficients of determination $\left(R^{2}\right)$ of $0.98,0.97$, and 0.99 for $180 \mathrm{~W}, 200 \mathrm{~W}$, and $220 \mathrm{~W}$, respectively. The specification limits (i.e., LSL, USL, CSL) are illustrated in Fig. 8 as a geometrical constraint.

Figure $9 \mathrm{a}-\mathrm{c}$ presents the measurements for the top width $\left(w_{\mathrm{T}}\right)$, middle width $\left(w_{\mathrm{M}}\right)$, and bottom width $\left(w_{\mathrm{B}}\right)$ of the spot welds produced with $180 \mathrm{~W}, 200 \mathrm{~W}$, and $220 \mathrm{~W}$, respectively. Our results show an increase of the bottom width $\left(w_{\mathrm{B}}\right)$ compared with the top width $\left(w_{\mathrm{T}}\right)$ when exposure time is increased. This tendency is observed using an average laser power of $200 \mathrm{~W}$ and $220 \mathrm{~W}$, which corresponds to the transition from the closed to an open keyhole weld pool and indicates the formation of a trapezoidal shape (Fig. 9b, c). In the

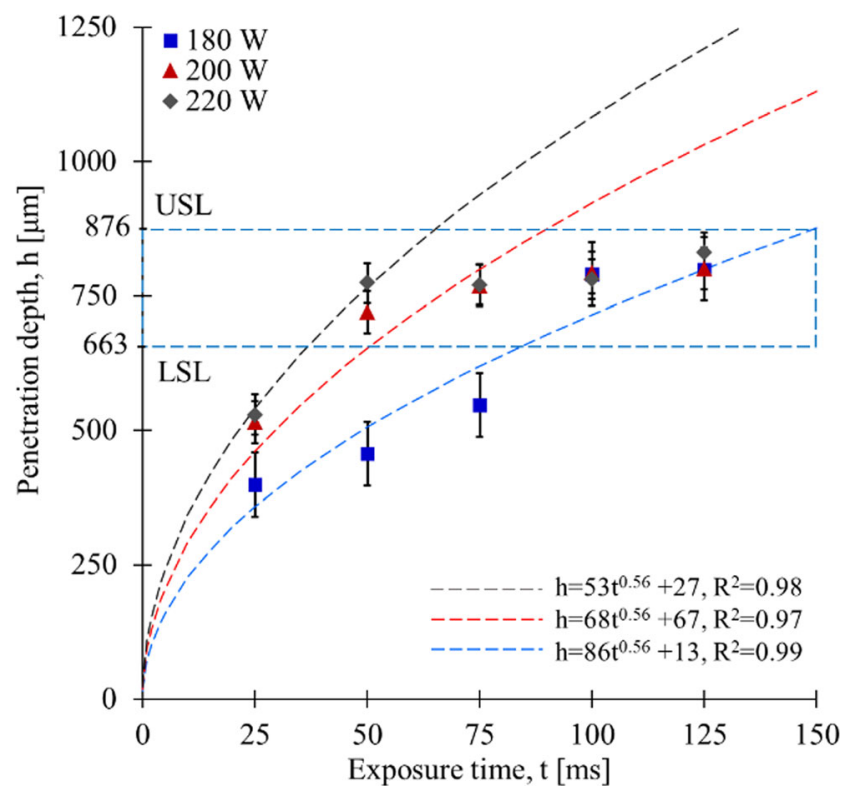

Fig. 8 Results for the measurement of the penetration depth $(h)$ 
case of samples produced with $180 \mathrm{~W}$ of average laser power (Fig. 9a), a top width $\left(w_{\mathrm{T}}\right)$ value is presented higher than bottom width $\left(w_{\mathrm{B}}\right)$ which corresponds to the transition of conduction regimen to close keyhole. According to Krasnosperov et al. [44], when the keyhole regime is established, there is an inherent non-uniformity caused by heat transference. In our experiments, it is observed as a change in widths reported in Fig. 9 (i.e., from 100 to 125 ms, Fig. 9c) which resulted asymmetric (see Fig. 7(b, c-e)). HAZ width $\left(b_{\mathrm{HAZ}}\right)$ is presented in Fig. 9d, and a tendency was observed: when average laser power increased, HAZ increased. According to Ventrella et al. [25], an increase in the HAZ width $\left(b_{\mathrm{HAZ}}\right)$ demonstrates a higher amount of energy dissipated in the material. The micro-spot welds obtained in this study presented heataffected zone width $\left(b_{\mathrm{HAZ}}\right)$ between 6 and $16 \mu \mathrm{m}$. These values are lower than the results of 25 to $50 \mu \mathrm{m}$ reported by Ventrella et al. [25] in the laser micro-seam welding of stainless steel. Our HAZ results are compared in range with the results reported by Siva Shanmugam et al. [13] in laser microspot welds of AISI 304.

The results obtained for the shape factor $\left(h / w_{\mathrm{T}}\right)$ are presented in Fig. 10. This factor was considered for the scaffold design. Although top width and penetration depth were measured for all samples, Fig. 10 shows the results where full penetration of the three sheets were obtained. Our results indicate that samples that produced a heat input of $11 \mathrm{~J}$ $\left(P_{\mathrm{AVG}}=220 \mathrm{~W}, t=50 \mathrm{~ms}\right), 18 \mathrm{~J}\left(P_{\mathrm{AVG}}=180 \mathrm{~W}, t=100\right.$ $\mathrm{ms})$, and $22.5 \mathrm{~J}\left(P_{\mathrm{AVG}}=180 \mathrm{~W}, t=125 \mathrm{~ms}\right)$ allowed it to maintain the shape factor constraint.

\subsection{Process efficiency modelling}

The computed efficiencies (i.e., coupling efficiency $\left(\eta_{\mathrm{C}}\right)$, melting efficiency $\left(\eta_{\mathrm{M}}\right)$, process efficiency $\left.\left(\eta_{\text {pro }}\right)\right)$ were calculated using Eqs. (5), (8), and (11). The results are displayed in Fig. 11. Micro-spot welds that accomplish full penetration depth (h) (i.e., 663 to $876 \mu \mathrm{m}$ ) presented values for the coupling efficiency $\left(\eta_{\mathrm{C}}\right)$ 85-86\% (11.0-27.5 J) which resulted higher in comparison to the samples that presented incomplete penetration (see Fig. 11a). Simonds et al. [41] measured the coupling efficiency by calorimetry using thermocouples and an optical sphere in micro-spot welds of AISI 316L sheets of $2 \mathrm{~mm}$ of thickness. They obtained results for the coupling efficiency between 80 and $90 \%$ for a heat input range of 4.6-6.3 J. These results are close in range to the coupling efficiency $\left(\eta_{\mathrm{C}}\right)$ calculated in this study for the experimental trials. Hipp et al. [15] accurately measured the melting efficiency for the plasma arc, laser, and hybrid laser (i.e., laserassisted plasma arc) welding processes in AISI 304 sheets of $1 \mathrm{~mm}$ of thickness using a thermographic camera. The results
Fig. 9 Results for the measurements of top width $\left(w_{\mathrm{T}}\right)$, middle width $\left(w_{\mathrm{M}}\right)$, and bottom width $\left(w_{\mathrm{B}}\right)$ for $\mathbf{a} 180 \mathrm{~W}, \mathbf{b} 200 \mathrm{~W}$, and $\mathbf{c} 220 \mathrm{~W}$ of average laser power $\left(P_{\mathrm{AVG}}\right)$ and $\mathbf{d}$ measured HAZ width $\left(b_{\mathrm{HAZ}}\right)$
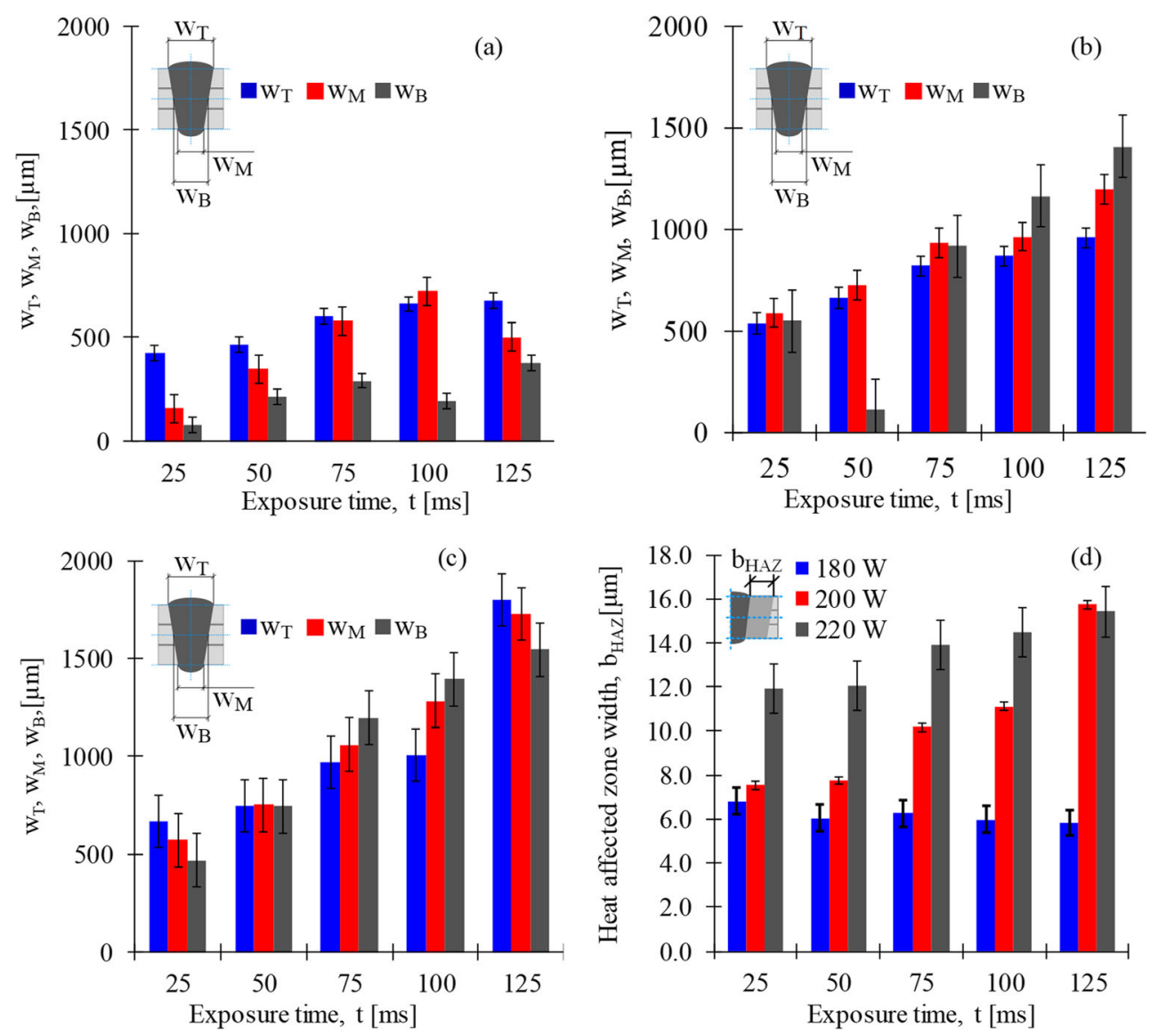


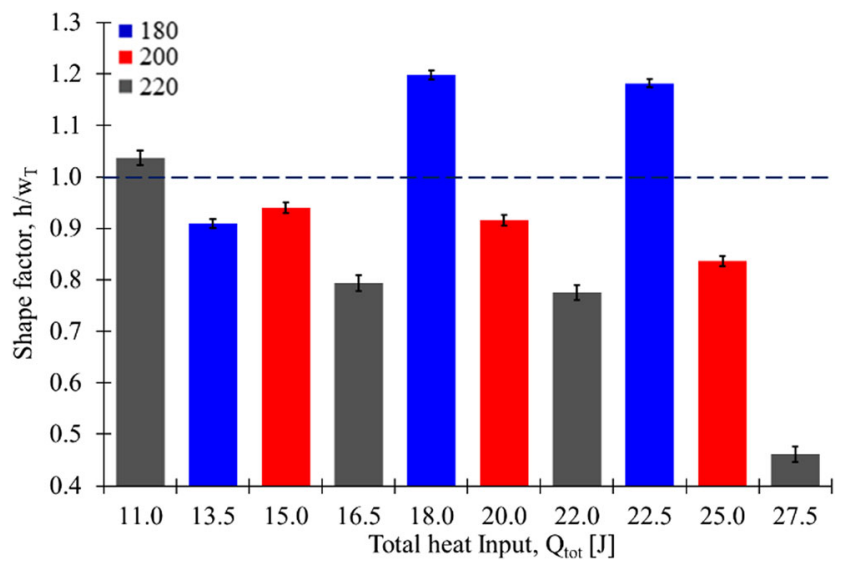

Fig. 10 Results of shape factor $\left(h / w_{\mathrm{T}}\right)$ for spot weld profile

were $22.1 \%, 11.5 \%$, and $35.6 \%$, for the plasma arc, laser, and hybrid laser, respectively. In this study, the spot welds fabricated with $180 \mathrm{~W}$ presented a melting efficiency between 7 and $12 \%$ (Fig. 11b) which are close in range with the values reported by Hipp et al. [15] for the laser welding process. Samples performed with $200 \mathrm{~W}$ and $220 \mathrm{~W}$ showed melting efficiencies between 22 and 38\% (Fig. 11b). These results indicated that laser micro-spot welding can achieve similar values for melting efficiency than plasma arc and hybrid laser welding. Additionally, the process' efficiency for the spot welds between 5 and $10 \%$ for $180 \mathrm{~W}$ and between 20 and $30 \%$ for $200-220 \mathrm{~W}$ (Fig. 11c).

\subsection{Model validation and fabrication of the porous scaffold}

Samples reported in Fig. 7 do not fulfill with all Class B quality requirements in the range of full penetration, due to the presence of a macro-central pore in the weld which would compromise the mechanical integrity of the weld. However, we observed that samples near full penetration do not present the macro-pore inside the weld (Fig. 7(a, f, k, 1)); therefore, we performed a new set of experiments based on previous process parameters. Samples produced with $220 \mathrm{~W}$ and $50 \mathrm{~ms}$ (i.e., a

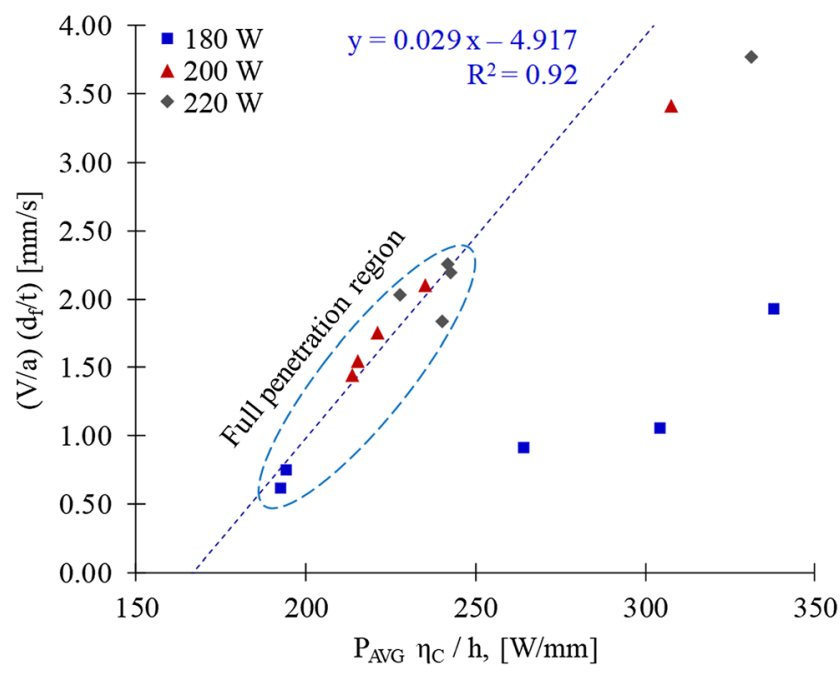

Fig. 12 Data of the preliminary study in the AISI 302 sheets (samples with full penetration are encircled) and linear regression model of the samples that achieved full penetration for the calculation of $\alpha_{n}$ processdependent factors of keyhole and conduction welding regimes

heat input of $11 \mathrm{~J}$ ) had full penetration, and HAZ width of $12 \mu \mathrm{m}$ had a process efficiency of $27 \%$ and a penetration depth/top width ratio value of 1.04 that complies with the required value of 1.0 mentioned above, although it has the presence of the central pore. Additionally, samples produced with $220 \mathrm{~W}$ and $25 \mathrm{~ms}$ showed lack of penetration. Our mathematical model was used to determine the required exposure time $(t)$ using Eq. (20) (i.e., Dausinger's adapted model for laser micro-spot welding). Through the obtained data from the experiments performed in the AISI 302 sheets and Eqs. (21) and (22), the values of $x$ and $y$ were calculated and displayed in Fig. 12. Then, the samples that achieved full penetration were selected. A linear model was fit to the data obtained with a coefficient of determination of 0.917 (see Fig. 12). Finally, using the results of the material properties for the AISI 302 alloy from Table 5 (Eqs. (23) and (24)), the factors $\alpha_{1}$ and $\alpha_{2}$ can be calculated for laser micro-spot welding. The results obtained were -1.13 and 0.24 for $\alpha_{1}$ and $\alpha_{2}$ respectively. Our study indicated that the adapted Dausinger's
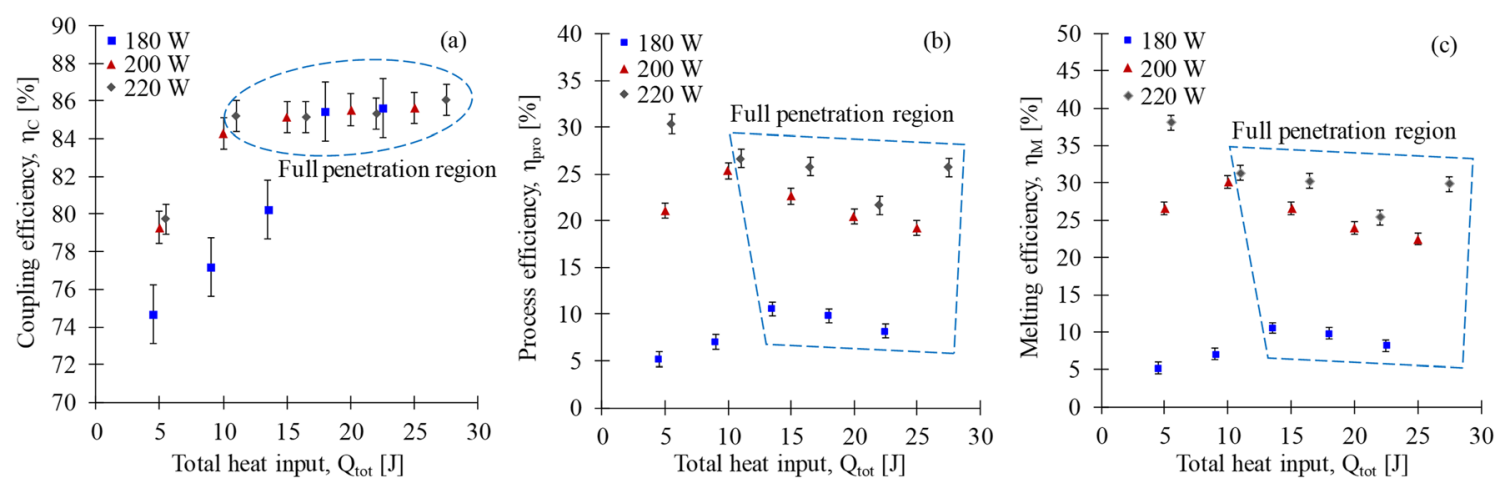

Fig. 11 Results of the calculated a coupling efficiency, $\mathbf{b}$ melting efficiency, and $\mathbf{c}$ process efficiency of the micro-spot welds performed in the AISI 302 sheets 
Fig. 13 Laser micro-spot welds performed with a $200 \mathrm{~W}, 65 \mathrm{~ms}$ $\left(Q_{\text {in }}=13 \mathrm{~J}\right)$, and b $220 \mathrm{~W}, 45 \mathrm{~ms}$ $\left(Q_{\text {in }}=9.90 \mathrm{~J}\right)$

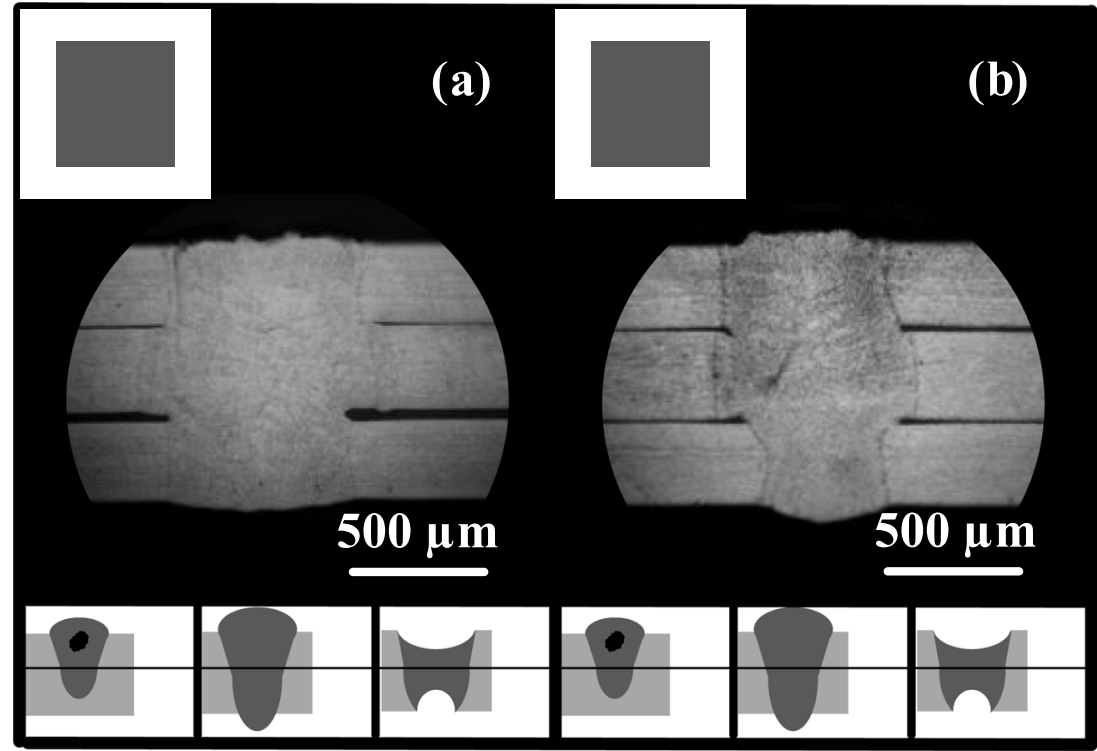

mathematical model can be used for the laser micro-spot welding to find the exposure time required in the range of full penetration.

$y=\frac{d_{\mathrm{f}}}{a}\left(\frac{V}{t}\right)$

$x=\frac{\eta_{\mathrm{C}} P_{\mathrm{AVG}}}{h}$

$a=\frac{\alpha_{2}}{\mathrm{Hp}}$

$b=\alpha_{1} \kappa_{\mathrm{AVG}}$

The average thermal diffusivity $\left(\kappa_{\mathrm{AVG}}\right)$ and the specific required heat $(\mathrm{Hp})$ (Table 5) were used in Eq. (20) to calculate the required exposure time $(t)$ to avoid the central pore inside the weld (see Fig. 7(b, h, n)). The results obtained for $\alpha_{1}$ and $\alpha_{2}$ of the keyhole welding regime (i.e., 200 to $220 \mathrm{~W}$ ) and a cylindrical weld volume were considered to calculate the cross-sectional area $(a)$ and the melted volume $(V)$. For calculations, laser spot diameters $\left(\Phi_{\mathrm{f}}\right)$ were maintained at $193 \mu \mathrm{m}$, while an average penetration depth $(h)$ was set at $774 \mu \mathrm{m}$ and top width $\left(w_{\mathrm{T}}\right)$ at $756 \mu \mathrm{m}$. According to the conceptual design, the penetration depth to top width ratio $\left(d / w_{\mathrm{T}}\right)$ must be greater than 1.0. After applying the proposed model, the exposure time $(t)$ calculated resulted in $45 \mathrm{~ms}$ and $65 \mathrm{~ms}$ for $220 \mathrm{~W}$ and $200 \mathrm{~W}$, respectively. Metallographic images were obtained to illustrate the cylindrical weld shape (see Fig. 13). Additionally, full penetration and the absence of internal pores were observed. Micro-spot weld produced with $200 \mathrm{~W}$ and $65 \mathrm{~ms}$ (Fig. 13a) presented a cross-sectional area greater than the weld fabricated with $220 \mathrm{~W}$ and $45 \mathrm{~ms}$ (Fig. 13b). This change in the cross-sectional area is caused by the difference in the total heat input $\left(Q_{\text {in }}\right)$ used to perform the welds. Our results indicate that the micro-spot weld presented an average penetration depth $(h)$ of $814 \mu \mathrm{m}$, which represents a
Fig. 14 a Final prototype fabricated and $\mathbf{b}$ sectional view of the laser micro-spot welds (a)

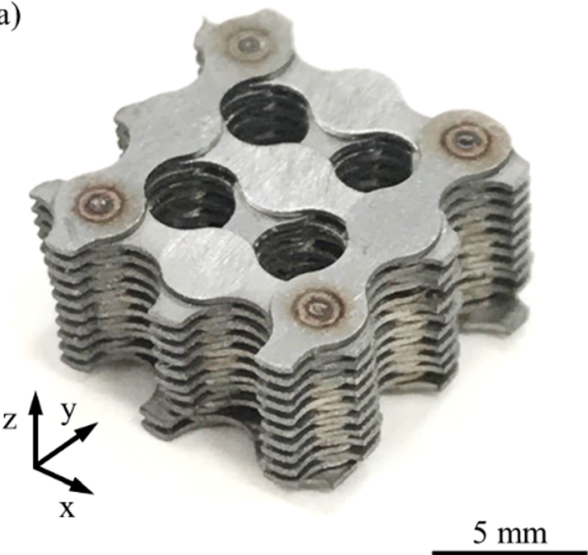

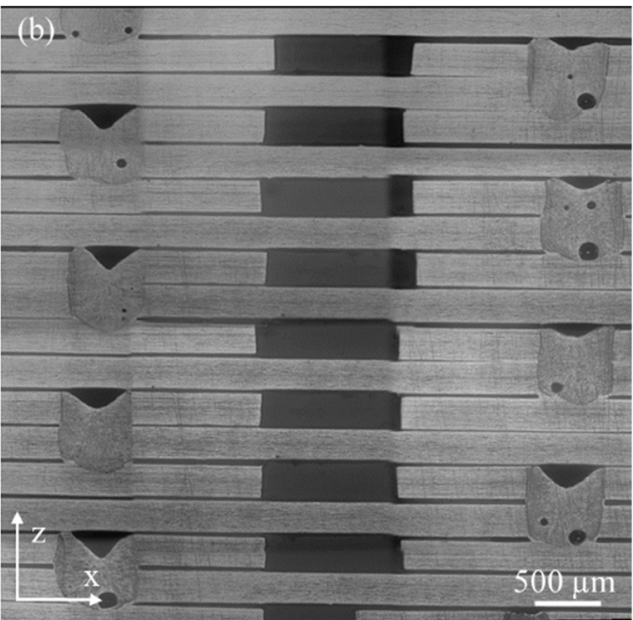


percentage error of around $4.9 \%$ from the estimated value of $774 \mu \mathrm{m}$. This result demonstrates an approximation to calculate exposure time and micro-spot welds with a cylindrical shape achieving a penetration depth to top width $\left(h / w_{\mathrm{T}}\right)$ ratio designed in a keyhole welding regime with a closed keyhole weld pool. Furthermore, in comparison to the samples produced with $200 \mathrm{~W}$ and $45 \mathrm{~ms}$, the process efficiency $\left(\eta_{\text {pro }}\right)$ was improved from 27 to $53 \%$ and the HAZ width $\left(b_{\mathrm{HAZ}}\right)$ was reduced from 12 to $8 \mu \mathrm{m}$.

Figure 14a displays the final prototype fabricated with the selected parameters $\left(P_{\mathrm{AVG}}=220, t=45 \mathrm{~ms}\right)$. Figure $14 \mathrm{~b}$ presents the cross-sectional view of the micro-spot welds. Figure 14a shows the micro-spot welds that correspond to the p1-p4 positions (Fig. 4d). These micro-spot welds are intercalated with the welds of the $\mathrm{p} 5-\mathrm{p} 8$ positions to fully join the scaffold (see Fig. 4e). Figure 14b displays the metallography of the micro-spot welds positioned in p4 and p8 (see Fig. $4 d$ ). The cross-sectional shapes of scaffold resulted in a rectangular cross-section which corresponds to the conduction welding regime. The micro-spot welds presented pores and shrinkage defects.

Pores and shrinkage (see Fig. 13) defects were not present in the three stacked experiments after using the welding parameters obtained with the proposed model. We suggest that these defects are the result of stacking more sheets. One proposal is to include in the model the heat losses caused by conduction of the sheet stacking. Further experiments can be performed to evaluate the effect of sheet number on scaffold's quality defects. Additionally, Harooni et al. [48] used the sheets preheating before welding process as a method to avoid these defects. Future work is oriented to analyze micro-hardness and compression tests to evaluate the mechanical properties of scaffold.

\section{Conclusions}

The laser micro-spot welding process was studied and successfully implemented in a sheet lamination-based methodology to fabricate austenitic stainless steel scaffolds. The conclusions can be summarized as follows:

- Welding regimes were identified for the laser micro-spot welding process. Samples in the closed keyhole regime presented rectangular cross-sectional shapes which were selected as the optimal shape to achieve higher mechanical strength.

- Visual inspection of the samples produced in open keyhole regime had larger number of defects than the samples produced in conduction and closed keyhole regime. This demonstrated that an open keyhole regime is more unstable compared to the conduction and closed keyhole regimes. Therefore, it is recommended to work with conduction and closed keyhole regimes to obtain micro-spot welds with a smaller number of defects.
- The results for the computed coupling, melting, and process efficiency are closed in range with values experimentally measured and reported in the literature. These results prove the accuracy and the reliability of the used Eqs. (5), (8), and (11) to estimate the process efficiencies of the laser micro-spot welding process. Furthermore, the computed process efficiencies indicated that laser micro-spot welds should be produced with $200 \mathrm{~W}$ or $220 \mathrm{~W}$ to obtain the highest efficiency level.

- Dausinger's mathematical model was successfully adapted to the laser micro-spot welding. The adapted model helped determine the required exposure time to produce micro-spot welds according to the scaffold's conceptual design and free of welding defects.

- Based on the adapted Dausinger's model, spot welds produced with $220 \mathrm{~W}$ and $45 \mathrm{~ms}$ presented a $5 \%$ error different from predicted. Besides, no defects were found and the spot welds achieved the Class B level according to the ISO 13919-1.

- A porous scaffold prototype was fabricated according to the conceptual design and using the process parameters selected with the help of the adapted mathematical model. This indicated the promising future of the methodology proposed to fabricate porous metallic scaffolds for bone tissue engineering applications through sheet laminationbased on micro-laser cutting and welding.

Acknowledgements We are grateful to the assistance received from Regina Elizabeth Vargas Mejia and Gabriel Soto Urzua. This work has been supported by the Advanced Manufacturing Focus Group of Tecnológico de Monterrey.

Author contribution Not applicable.

Data availability The datasets generated and analyzed during the current study are available from the corresponding author on reasonable request.

Code availability Not applicable.

\section{Declarations}

Ethics approval Not applicable.

Consent to participate Not applicable.

Consent for publication Not applicable.

Conflict of interest The authors declare no competing interests.

Open Access This article is licensed under a Creative Commons Attribution 4.0 International License, which permits use, sharing, adaptation, distribution and reproduction in any medium or format, as long as you give appropriate credit to the original author(s) and the source, provide a link to the Creative Commons licence, and indicate if changes were made. The images or other third party material in this article are included in the article's Creative Commons licence, unless indicated otherwise in a credit line to the material. If material is not included in the article's 
Creative Commons licence and your intended use is not permitted by statutory regulation or exceeds the permitted use, you will need to obtain permission directly from the copyright holder. To view a copy of this licence, visit http://creativecommons.org/licenses/by/4.0/.

\section{References}

1. Wu S, Liu X, Yeung KWK, Liu C, Yang X (2014) Biomimetic porous scaffolds for bone tissue engineering. Mater Sci Eng R 80: 1-36. https://doi.org/10.1016/j.mser.2014.04.001

2. Alvarez K, Nakajima H (2009) Metallic scaffolds for bone regeneration. Materials (Basel) 2:790-832. https://doi.org/10.3390/ ma2030790

3. Grygier D, Hoppe V, Ziety A, Rutkowka-Gorczyca M (2018) Evaluation of differentiation of structural and physico-chemical properties of orthodontic wires of AISI304 stainless steel. Eng Biomater 146:8-13

4. Tan XP, Tan YJ, Chow CSL et al (2017) Metallic powder-bed based 3D printing of cellular scaffolds for orthopaedic implants: a state-of-the-art review on manufacturing, topological design, mechanical properties and biocompatibility. Mater Sci Eng C 13281343. https://doi.org/10.1016/j.msec.2017.02.094

5. Dewidar MM, Khalil KA, Lim JK (2007) Processing and mechanical properties of porous 3 16L stainless steel for biomedical applications. Trans Nonferrous Metals Soc China 17:468-473

6. Čapek J, Vojtěch D (2013) Properties of porous magnesium prepared by powder metallurgy. Mater Sci Eng C 33:564-569. https:// doi.org/10.1016/j.msec.2012.10.002

7. Xu B, Wu XY, Lei JG, Luo F, Gong F, du CL, Sun XQ, Ruan SC (2013) Research on micro-electric resistance slip welding of copper electrode during the fabrication of 3D metal micro-mold. J Mater Process Technol 213:2174-2183. https://doi.org/10.1016/j. jmatprotec.2013.06.009

8. Lei J, Wu X, Wu B, Xu B, Guo D, Zhong J (2016) Fabrication of $3 \mathrm{D}$ microelectrodes by combining wire electrochemical micromachining and micro-electric resistance slip welding. Procedia CIRP 42:825-830. https://doi.org/10.1016/j.procir.2016. 03.002

9. Hung CH, Sutton A, Li Y, Shen Y, Tsai HL, Leu MC (2019) Enhanced mechanical properties for 304L stainless steel parts fabricated by laser-foil-printing additive manufacturing. J Manuf Process 45:438-446. https://doi.org/10.1016/j.jmapro.2019.07.030

10. Narayan R, Goering P, Editors G (2011) Laser micro-and nano fabrication of biomaterials. Mater Res Soc Bull 36:973-982. https://doi.org/10.1557/mrs.2011.302

11. Sun J, Nie P, Feng K, Li Z, Guo B, Jiang E (2017) The elimination of pores in laser welds of AISI 304 plate using different shielding gases. J Mater Process Technol 248:56-63. https://doi.org/10.1016/ j.jmatprotec.2017.05.011

12. Kumar N, Mukherjee M, Bandyopadhyay A (2017) Comparative study of pulsed Nd:YAG laser welding of AISI 304 and AISI 316 stainless steels. Opt Laser Technol 88:24-39. https://doi.org/10. 1016/j.optlastec.2016.08.018

13. Siva Shanmugam N, Buvanashekaran G, Sankaranarayanasamy K (2012) Some studies on weld bead geometries for laser spot welding process using finite element analysis. Mater Des 34:412426. https://doi.org/10.1016/j.matdes.2011.08.005

14. Cedeño-Viveros LD, García-López E, Vázquez E V, et al (2018) Laser micro-spot wleding of AISI 302 stainless steel sheets. In: Proceedings of SPIE - Laser -based Micro and Nanoprocessing XII. San Francisco, p 105
15. Hipp D, Mahrle A, Jäckel S, Beyer E, Leyens C, Füssel U (2018) Method for high accuracy measurements of energy coupling and melting efficiency under welding conditions. J Laser Appl 30: 032414. https://doi.org/10.2351/1.5040615

16. Patschger A, Bliedtner J, Bergmann JP (2013) Approaches to increase process efficiency in laser micro welding. Phys Procedia 41: 592-602. https://doi.org/10.1016/j.phpro.2013.03.121

17. Tadamalle AP, Reddy YP, Ramjee E, Reddy V (2014) Evaluation of Nd: YAG laser welding efficiencies for 304L stainless steel. Procedia Mater Sci 6:1731-1739. https://doi.org/10.1016/j.mspro. 2014.07.160

18. Kleine KF, Whitney B, Watkins KG (2002) Use of fiber lasers for micro cutting applications in the medical device industry. In: ICALEO 2002 - 21st International Congress on Applications of Laser and Electro-Optics. Scottsdale

19. Ely KJ, Hall P, Zhou Y (2013) Microwelding methods in medical components and devices. Woodhead Publishing Limited

20. Itälä AI, Ylänen HO, Ekholm C, Karlsson KH, Aro HT (2001) Pore diameter of more than $100 \mu \mathrm{m}$ is not requisite for bone ingrowth in rabbits. J Biomed Mater Res 58:679-683. https://doi.org/10.1002/ jbm. 1069

21. Geng F, Tan L, Zhang B et al (2009) Study on beta-TCP coated porous $\mathrm{Mg}$ as a bone tissue engineering scaffold material. J Mater Sci Technol 25:123-129

22. Yu W, Zhao H, Ding Z, Zhang Z, Sun B, Shen J, Chen S, Zhang B, Yang K, Liu M, Chen D, He Y (2016) In vitro and in vivo evaluation of MgF 2 coated AZ31 magnesium alloy porous scaffolds for bone regeneration. Colloids Surf B: Biointerfaces 149:330-340. https://doi.org/10.1016/j.colsurfb.2016.10.037

23. Yazdimamaghani M, Razavi M, Vashaee D, Moharamzadeh K, Boccaccini AR, Tayebi L (2017) Porous magnesium-based scaffolds for tissue engineering. Mater Sci Eng C 71:1253-1266. https://doi.org/10.1016/j.msec.2016.11.027

24. P'ng D, Molian P (2008) Q-switch Nd:YAG laser welding of AISI 304 stainless steel foils. Mater Sci Eng A 486:680-685. https://doi. org/10.1016/j.msea.2007.08.063

25. Ventrella VA, Berretta JR, de Rossi W (2010) Pulsed Nd:YAG laser seam welding of AISI 316L stainless steel thin foils. J Mater Process Technol 210:1838-1843. https://doi.org/10.1016/j. jmatprotec.2010.06.015

26. Solati A, Bani Mostafa Arab N, Mohammadi-Ahmar A, Fazli Shahri HR (2019) Multi-criteria optimization of weld bead in pulsed Nd:YAG laser welding of stainless steel 316. Proc Inst Mech Eng Part E J Process Mech Eng 233:151-164. https://doi. org/10.1177/0954408918756654

27. ISO (2019) ISO-13919-1: 2019 - Electron and laser beam welded joints - guidance on quality levels fo imperfections.

28. Čapek J, Machová M, Fousová M, Kubásek J, Vojtěch D, Fojt J, Jablonská E, Lipov J, Ruml T (2016) Highly porous, low elastic modulus $316 \mathrm{~L}$ stainless steel scaffold prepared by selective laser melting. Mater Sci Eng C 69:631-639. https://doi.org/10.1016/j. msec.2016.07.027

29. ASTM ASTM E1024 - 97: Standard guide for chemical analysis of metals and metal bearing ores by flame atomic absorption spectrophotometry.

30. ASTM (2017) ASTM E3 - 11: Standard guide for preparation of metallographic specimens

31. Khan MMA, Romoli L, Dini G, Fiaschi M (2011) A simplified energy-based model for laser welding of ferritic stainless steels in overlap configurations. CIRP Ann - Manuf Technol 60:215-218. https://doi.org/10.1016/j.cirp.2011.03.112

32. Erika G-L, Alexis M-T, Juansethi I-M, R. SH, Alex EZ, Ciro AR (2016) Fiber laser microcutting of AISI 316L stainless steel tubesinfluence of pulse energy and spot overlap on back wall dross. Procedia CIRP 49:222-226. https://doi.org/10.1016/j.procir.2015. 11.020 
33. Penner D, Bernstein IM (1977) Handbook of stainless steels. McGraw-Hill

34. Keicher DM (1995) Laser beam characterization results for a high power CW Nd:YAG laser. Sandia Natl Lab P

35. Swift-hook DT, Gick AEF (1973) Penetration welding with lasers. Weld Res Suppl:492-499

36. He X, Norris JT, Fuerschbach PW, Debroy T (2006) Liquid metal expulsion during laser spot welding of 304 stainless steel. J Phys D Appl Phys J Phys D Appl Phys 39:525-534. https://doi.org/10. 1088/0022-3727/39/3/016

37. Patschger A, Bliedtner J (2017) Constraints and optimization of the laser microwelding process of thin metal foils. J Laser Appl 29: 022408. https://doi.org/10.2351/1.4983504

38. Sakamoto H, Iwase T, Shibata K (2004) The effect of twin spot beam arrangement on energy coupling during welding. Study of twin spot Nd: YAG laser welding of aluminium alloys. Weld Int 18:677-682. https://doi.org/10.1533/wint.2004.3316

39. Fuerschbach PW, Eisler GR (1999) Effect of very high travel speeds on melting efficiency in laser beam welding. SAE Tech Pap 108:1-7. https://doi.org/10.4271/1999-01-0996

40. Dausinger F (1995) Strahlwerkzeug Laser: Energiekopplung und Prozesseffektivität. Teubner, Laser in der Materialbearbeitung

41. Simonds BJ, Sowards J, Hadler J, Pfeif E, Wilthan B, Tanner J, Harris C, Williams P, Lehman J (2018) Time-resolved absorptance and melt pool dynamics during intense laser irradiation of a metal. Phys Rev Appl 10:1. https://doi.org/10.1103/PhysRevApplied.10. 044061

42. Akbari M, Saedodin S, Toghraie D, Shoja-Razavi R, Kowsari F (2014) Experimental and numerical investigation of temperature distribution and melt pool geometry during pulsed laser welding of Ti6Al4V alloy. Opt Laser Technol 59:52-59. https://doi.org/ 10.1016/j.optlastec.2013.12.009

43. Bannour S, Abderrazak K, Mhiri H, Le Palec G (2012) Effects of temperature-dependent material properties and shielding gas on molten pool formation during continuous laser welding of AZ91 magnesium alloy. Opt Laser Technol 44:2459-2468. https://doi. org/10.1016/j.optlastec.2012.03.034

44. Krasnoperov MY, Pieters RRGM, Richardson IM (2004) Weld pool geometry during keyhole laser welding of thin steel sheets. Sci Technol Weld Join 9:501-506. https://doi.org/10.1179/ 136217104225021733

45. Zhu J, Li L, Liu Z (2005) CO2 and diode laser welding of AZ31 magnesium alloy. Appl Surf Sci 247:300-306. https://doi.org/10. 1016/j.apsusc.2005.01.162

46. Katayama S (2013) Defect formation mechanisms and preventive procedures in laser welding

47. Khan MMA, Romoli L, Fiaschi M, Dini G, Sarri F (2011) Experimental design approach to the process parameter optimization for laser welding of martensitic stainless steels in a constrained overlap configuration. Opt Laser Technol 43:158-172. https://doi. org/10.1016/j.optlastec.2010.06.006

48. Harooni M, Ma J, Carlson B, Kovacevic R (2015) Two-pass laser welding of AZ31B magnesium alloy. Mater Process Technol 216: 114-122. https://doi.org/10.1016/j.jmatprotec.2014.08.028

Publisher's note Springer Nature remains neutral with regard to jurisdictional claims in published maps and institutional affiliations. 